\title{
Elucidating The Thermal Decomposition Mechanism and Pyrolysis Characteristics of Biorefinery-Derived Humins From Sugarcane Bagasse And Rice Husk
}

Julio César de Jesus Gariboti

Federal University of Sao Paulo: Universidade Federal de Sao Paulo

Marina Gontijo Souza Macedo

Federal University of Sao Paulo: Universidade Federal de Sao Paulo

Vinícius Matheus Silva Macedo

Federal University of Sao Paulo: Universidade Federal de Sao Paulo

Yesid Javier Rueda-Ordóñez

Industrial University of Santander: Universidad Industrial de Santander

Emília Savioli Lopes

State University of Campinas: Universidade Estadual de Campinas

Jonathan Tenorio Vinhal

University of Sao Paulo: Universidade de Sao Paulo

Eliezer Ladeia Gomes

Federal University of Sao Paulo: Universidade Federal de Sao Paulo

Jorge Alberto Soares Tenório

University of Sao Paulo: Universidade de Sao Paulo

Romilda Fernandez Felisbino

Federal University of Sao Paulo: Universidade Federal de Sao Paulo

Melina Savioli Lopes

Federal University of Alfenas: Universidade Federal de Alfenas

Laura Plazas Tovar ( $\sim$ laura.tovar@unifesp.br)

Universidade Federal de São Paulo - Campus Diadema Unidade José de Filippi: Universidade Federal de Sao Paulo - Campus Diadema https://orcid.org/0000-0003-1001-9250

\section{Research Article}

Keywords: Humins, Isoconversional Methods, Rice husk, Sugarcane bagasse, Thermochemical processes

Posted Date: November 30th, 2021 
DOI: https://doi.org/10.21203/rs.3.rs-1113693/v1

License: (c) (1) This work is licensed under a Creative Commons Attribution 4.0 International License. Read Full License 


\section{Elucidating the thermal decomposition mechanism and pyrolysis characteristics of biorefinery-derived humins from sugarcane bagasse and rice husk}

Julio César de Jesus Garibotia, Marina Gontijo Souza Macedoa, Vinícius Matheus Silva Macedo ${ }^{a}$, Yesid Javier Rueda-Ordóñez ${ }^{b}$, Emília Savioli Lopes ${ }^{c}$, Jonathan Tenorio Vinhal ${ }^{d}$, Eliezer Ladeia Gomesa, Jorge Alberto Soares Tenório ${ }^{d}$, Romilda Fernandez Felisbino ${ }^{a}$, Melina Savioli Lopes ${ }^{\mathrm{e}}$, Laura Plazas Tovar ${ }^{\mathrm{a}^{*}}$

\footnotetext{
${ }^{a}$ Department of Chemical Engineering, Federal University of São Paulo, ZIP code 09913-030, Diadema-SP, Brazil.

b Department of Mechanical Engineering, Industrial University of Santander, ZIP code 680002, Bucaramanga, Colombia.

'School of Chemical Engineering, University of Campinas, ZIP code 13083-852, Campinas-SP, Brazil.

d Department of Chemical Engineering, University of São Paulo, ZIP code 05508-080, São Paulo-SP, Brazil.

e Department of Chemical Engineering, Federal University of Alfenas, ZIP code 37715-400, Poços de Caldas-MG, Brazil.
}

*To whom correspondence should be addressed: e-mail: laura.tovar@unifesp.br

ORCID:

Marina Gontijo Souza Macedo: 0000-0003-4023-4285

Yesid Javier Rueda-Ordóñez: 0000-0002-8533-3108

Emília Savioli Lopes: 0000-0003-4754-9204

Jonathan Tenorio Vinhal: 0000-0002-4391-2443

Eliezer Ladeia Gomes: 0000-0002-5250-8282

Jorge Alberto Soares Tenório: 0000-0002-7849-7470

Romilda Fernandez Felisbino: 0000-0003-2855-5449

Melina Savioli Lopes: 0000-0001-9379-9752

Laura Plazas Tovar: 0000-0003-1001-9250 


\section{Abstract}

Biomass-derived humins produced in the biorefining of biomass represent an attractive feedstock for thermochemical processes and other carbon-derived platform chemicals. However, in most works, humins are merely a by-product that is not further analyzed. This work presents the purification and characterization of humins derived from sugarcane bagasse and rice husks ( $\mathrm{H}-\mathrm{SCB}$ and $\mathrm{H}-\mathrm{RH}$ respectively), followed by the kinetic and thermodynamic analysis of its pyrolysis. Pyrolysis was examined via thermogravimetric analysis (TGA), and a global reaction model was adopted to address pyrolysis kinetics. To understand the pyrolysis process of humins and boost the quality of fit between the kinetic model and thermoanalytical data, the analyses were based on the Vyazovkin isoconversional method. The activation energy of $\mathrm{H}-\mathrm{SCB}$ increased from 166.09 to $329.76 \mathrm{~kJ} \mathrm{~mol}^{-1}$. In contrast, the activation energy of $\mathrm{H}-\mathrm{RH}$ decreased from 163.31 to $84.99 \mathrm{~kJ} \mathrm{~mol}^{-1}$. According to the results of the generalized master plot approach, the governing reaction mechanism shifted among order-based models, nucleation, and diffusion-controlled particle mechanisms. Derived thermodynamic properties showed that the heat absorbed helps the humins to achieve a more ordered state close to a conversion of 0.50 . As far as we know, these findings are the first reported data on the forecast kinetic curves and pyrolysis mechanism of biorefinery-derived humins from sugarcane bagasse and rice husk, and these results will enable process design for the thermochemical conversion of these emerging materials to produce energy and other products.

Keywords: Humins, Isoconversional Methods, Rice husk, Sugarcane bagasse, Thermochemical processes 


\section{Introduction}

Circular chemistry is proposed as a solution to secure the development of a sustainable future. This approach includes increased waste treatment, reuse, and recovery (including by-products) to reduce the use of natural resources [1]. Levulinic acid is currently debated as a promising platform chemical [2]. However, the production of levulinic acid in this concept of circular chemistry is broken because of the formation of a carbonaceous by-product, known as humins, during the acid-catalyzed dehydration of carbohydrates to produce levulinic acid [2-5]. Humins are currently considered green precursors or potential fuel for biorefinery process [6]. They are formed of macromolecules with a maximum carbon composition of $65 \%$ [7-9]. Its chemical structure is rich in furans, carboxyl groups, ketones, and hydroxyl groups $[10,11]$. Furthermore, humins have a variety of components in smaller quantities, such as carbohydrates, peptidoglycans, and peptides derived from lignin [2].

Currently, most of the research on the valorization of humins-based products is focused on the synthesis of thermoset polymers [12], copolymers with elastomeric characteristics [13], matrices for impregnation of catalysts [14], preparation of resins [15], and production of cyclic and aromatic hydrocarbons [16], or as a fuel for heat and power generation [17]. According to the results reported in these studies, there are thermal properties of humins that indicate a great potential for their application in thermochemical conversion. Humins are extremely important because they are powerful sources of energy when submitted to the pyrolysis process $[2,18]$. Pyrolysis, a technology in which the material is thermally decomposed in an inert atmosphere and at high temperatures, produces bio-liquids, biochar, and pyrolysis gas, which are products that can be used as feedstock for fuels and chemicals [19].

Humins resulting from the acidic treatment of carbohydrates [12] or synthesized in industrial processes $[20,12]$ showed the volatilization of residual water and volatile organic components under pyrolysis conditions. The humins produced by Avantium Chemicals exhibited in their degradation profile a devolatilization (120 to $270{ }^{\circ} \mathrm{C}$ ), followed by dehydration, decarboxylation, and decarbonylation reactions [21]. Two previous works determined the kinetic parameters of humin pyrolysis through linear 
differential and integral isoconversional methods [22,23]. Cortés and Bridgwater [23] described the pyrolysis of the solid residue of hydrolysis of miscanthus by the third-order reaction mechanism and estimated activation energy of $155 \mathrm{~kJ} \mathrm{~mol}^{-1}$. However, there was not enough evidence to support the mechanism selection given the significant discrepancy when compared to the experimental data. Wang et al. [22] interpreted the pyrolysis of humins by the one-step global reaction. Also, they determined the mean pyrolysis energy of humins obtained by acid hydrolysis of commercial xylose (150.68 kJ $\left.\mathrm{mol}^{-1}\right)$ and glucose $\left(163 \mathrm{~kJ} \mathrm{~mol}^{-1}\right)$. Sbirrazzuoli [24] and Sangregorio et al. [25] calculated the activation energy for humins (supplied by Avantium N.V.) using non-isothermal rheometry and the data were interpreted by isoconversional methods. Sbirrazzuoli [24] stated that the activation energy ranged from 25 to $110 \mathrm{~kJ} \mathrm{~mol}^{-1}$, highlighting some individual processes: (i) uncatalyzed crosslinking of crude humins, (ii) diffusion as a ratecontrolling step at the end of the reaction, and (iii) molecular mobility intensification, where the conversion rate is governed by movements of longer chain segments. Similarly, Sangregorio et al. [25] reported a decrease between 10 and $60 \mathrm{~kJ} \mathrm{~mol}^{-1}$, attributing this decrease to the governance of a kinetic diffusion mechanism for conversion greater than $40 \%$.

However, there are no reports on the investigation of pyrolysis behavior of humins derived from sugarcane bagasse or rice husks, which are two agro-industrial residues with great potential to be used in biorefineries [reference]. In this work, humins obtained from hydrolysis/dehydration reactions of sugarcane bagasse and rice husk were investigated. The humins were purified and characterized. Thermoanalytical data and kinetic calculations were performed to analyze the behavior of pyrolysis considering a one-step global single reaction $[22,23]$. The kinetic parameters were computed using the model-free kinetics method, based on Vyazovkin's isoconversional technique describing an advanced nonlinear isoconversional method. The reaction mechanism was revealed from the master plot methodology that allowed the investigation of 39 kinetic mechanisms. Furthermore, a shift in the reaction mechanism was shown by variations in the activation energy. This work overcomes the main drawback with numerical instabilities introduced by the linear isoconversional methods reported by other authors 
$[22,23]$ and also presents an analysis of the thermodynamic parameters of the thermal/pyrolysis decomposition of humins. Therefore, these results represent an important milestone in the design of new processes for the valorization of humins in advanced and integrated biorefineries, thus contributing to the development of circular chemistry in biorefinery processes focused on the production of levulinic acid.

\section{Materials and Method}

\subsection{Agro-industrial acid hydrolysis residue and chemicals}

Acid hydrolysis residues (ARH) were obtained from the biorefining of the agroindustrial residues sugarcane bagasse $(\mathrm{SCB})$ and rice husk $(\mathrm{RH})$ in a three-step process which consisted of an acid pretreatment followed by alkaline treatment and catalytic cellulose depolymerization to produce levulinic acid, as proposed in previous works $[5,4,3]$. The acid pre-treatment comprised of a prehydrolysis of the biomass (SCB or RH) with a solution of sulfuric acid $(1.0 \% \mathrm{w} / \mathrm{v})$ at $121{ }^{\circ} \mathrm{C}$ for a residence time of $90 \mathrm{~min}$ with $20 \%$ of solids loading. In the second step of the process, the insoluble solid fraction (ISFI) obtained from the previous step was treated with sodium hydroxide $(0.5 \% \mathrm{w} / \mathrm{v}$ for SCB and $2.0 \% \mathrm{w} / \mathrm{v}$ for $\mathrm{RH}$ ) at $121{ }^{\circ} \mathrm{C}$ for $90 \mathrm{~min}$ with $20 \%$ of solids loading. This stage produced a second water-insoluble solid fraction (ISF-II). Using ISF-II, the last stage was performed under optimized conditions determined by Lopes et al. [4] of $190{ }^{\circ} \mathrm{C}, 7.0 \%$ $\mathrm{w} / \mathrm{v}$ sulfuric acid for 75 min with $12 \%$ of solids loading. After the reaction, the products were separated by vacuum filtration $(0.22 \mu \mathrm{m}$ polyvinylidene fluoride membrane) into a liquid fraction (characterized in previous work [4]) and a water-insoluble solid fraction, which corresponds to the AHR. The AHR was resuspended in distilled water to remove residual sugars and organic acids. The remaining material was dried in an oven at $60^{\circ} \mathrm{C}$ for $24 \mathrm{~h}$ and stored in a vacuum desiccator for purification and physicochemical characterization.

Suppliers and purities of chemicals are listed in Table S1 - Supplementary Information. Ultrapure deionized water (18 $\mathrm{M} \Omega \mathrm{cm}$ resistivity, Milli-Q, Millipore) was used. 


\subsection{Purification}

The purification of AHR from SCB and RH was performed based on the methods presented by Chang et al. [26] and Song et al. [27], with adaptations. Samples were acidified with a $1 \mathrm{~mol} \mathrm{~L}^{-1} \mathrm{HCl}$ until reaching a $\mathrm{pH}$ between 1 and 2; then, the samples were washed with deionized water to remove the acid solution. The resulting solid was subjected to three extraction processes. Firstly, a $1 \mathrm{~mol} \mathrm{~L}^{-1} \mathrm{NaOH}$ solution was used repetitively till reach a $\mathrm{pH}$ of 12.6 . Then, the second extraction was performed with a 6 mol L-1 urea $\left(\left(\mathrm{NH}_{2}\right)_{2} \mathrm{CO}\right)$ and $0.1 \mathrm{~mol} \mathrm{~L}^{-1} \mathrm{NaOH}$, in each extraction. The solution was centrifuged (2500 rpm for $30 \mathrm{~min}$ ) and kept at $25{ }^{\circ} \mathrm{C}$ for $24 \mathrm{~h}$. The supernatant fraction was removed and its $\mathrm{pH}$ was adjusted to $7-8$ with a $1 \mathrm{~mol} \mathrm{~L}^{-1} \mathrm{HCl}$ solution. To remove the alkaline solution and urea, the supernatant fraction was washed with deionized water and then dried in an oven at $60^{\circ} \mathrm{C}$ for $48 \mathrm{~h}$. Finally, the resulting solid was extracted with a solution of DMSO (dimethylsulfoxide) and $\mathrm{H}_{2} \mathrm{SO}_{4}$ in a volume ratio of $94: 6$ for $18 \mathrm{~h}$. The solids were then separated from the $\mathrm{DMSO} / \mathrm{H}_{2} \mathrm{SO}_{4}$ solution by centrifugation at $15.000 \mathrm{x}$ g. The solutions collected for each extraction were combined and diluted with water until a pH of 2 was obtained. The solution was kept overnight at $4{ }^{\circ} \mathrm{C}$ to allow precipitation of humins. The released solids were isolated and dehydrated with $0.3 \mathrm{~mol} \mathrm{~L}^{-1} \mathrm{HF} / 0.1 \mathrm{~mol} \mathrm{~L}^{-}$

${ }^{1} \mathrm{HCl}(50 \mathrm{~mL})$, washed with distilled water, and dried to obtain the humins, referred here as $\mathrm{H}-\mathrm{SCB}$ and $\mathrm{H}-\mathrm{RH}$ for humins derived from $\mathrm{SCB}$ and humins derived from $\mathrm{RH}$, respectively. Humins were weighed and their yield was expressed in $\mathrm{g}$ per $100 \mathrm{~g}$ of biomass, in dry weight. The samples were stored in a desiccator for further characterization and analysis.

\subsection{Structural characterization}

The surface morphology of the humins was investigated using scanning electron microscopy (SEM, JEOL JSM-7401F, Jeol Ltd., Japan). The samples were deposited on a carbon strip and inserted into a vacuum chamber to be covered with a gold film before analysis. The Fourier transform infrared spectroscopy (FT-IR, Shimadzu/IR Prestige 21 spectrometer, Shimadzu Corporation, Japan) was used as a qualitative verification of functional groups. All humin samples were analyzed under ambient conditions. A portion 
of the sample was ground with $\mathrm{KBr}(1 \% \mathrm{w} / \mathrm{w})$ and compressed under a pressure of $10 \mathrm{kN}$ for 5 minutes. The spectra were acquired under a transmittance regime, performing 100 scans over 4000 to $500 \mathrm{~cm}^{-1}$ with a $4 \mathrm{~cm}^{-1}$ resolution. To ensure the quality of the analysis, the correction of the obtained spectrum was carried out and the background analysis of the FT-IR empty camera was carried out before each scan so that it was possible to remove the noise from the final spectra. The selected spectra were normalized to a total area of 100.

Moisture content was determined in accordance with the ASTM D3173 standard method [28] as the mass loss after drying at $105{ }^{\circ} \mathrm{C}$. Ash content was determined according to the standardized method ASTM D3174 [29]. To determine volatile matter (VM), the standardized protocol ASTM D3175 [30] was used. Fixed carbon (FC) was determined by difference ( $\mathrm{FC}=100 \%$ - VM - ashes).

The higher heating value (HHV) was determined with a calorimetric bomb (Adiabatic Calorimeter, Parr Instrument Company, USA) with excess oxygen at a pressure of 30 bar. The equipment was calibrated with benzoic acid $\left(\mathrm{C}_{6} \mathrm{H}_{5} \mathrm{COOH}\right)$. The composition of elements $\mathrm{C}, \mathrm{H}$, and $\mathrm{O}$ was determined from empirical correlations presented in Equations (1) to (3) developed by Nhuchhen [31], with average absolute error of $0.45 \%, 2.82 \%$, $2.01 \%$, respectively.

$$
\begin{aligned}
& H=55.36778-0.4830 V M-0.5319 F C-0.56 \text { Ashes } \\
& \mathrm{C}=-35.9972+0.7698 V M+1.3269 F C+0.3250 \text { Ashes } \\
& O=223.6805-1.7226 V M-2.2296 F C-2.2463 \text { Ashes }
\end{aligned}
$$

\subsection{Thermogravimetric analysis (TGA)}

Thermal/pyrolysis degradation of humins was conducted using a DTG-60H thermogravimetric analyzer (Shimadzu Corporation, Japan). Initially, to remove all atmospheric gases, the thermogravimetric analysis began with the setting of the furnace cell with a $50 \mathrm{~mL} \mathrm{~min}{ }^{-1}$ flow of nitrogen gas for $20 \mathrm{~min}$ at $30^{\circ} \mathrm{C}$. Then, to ensure complete evaporation of moisture, the temperature was increased to $120^{\circ} \mathrm{C}$. Thermogravimetric analysis was performed under non-isothermal conditions at three different heating rates $\left(15,20\right.$, and $30{ }^{\circ} \mathrm{C} \min ^{-1}$ for SCB and 10,20 and $30{ }^{\circ} \mathrm{C} \mathrm{min}^{-1}$ for $\left.\mathrm{RH}\right)$, selected in previous 
tests between 5 and $40{ }^{\circ} \mathrm{C} \min ^{-1}$, up to $800{ }^{\circ} \mathrm{C}$ (data not shown) showing lower noise in the TGA mass/temperature curves. Using an analytical computer system, the loss of mass as a function of temperature and the derivative thermogravimetry (DTG) were recorded. Solid residue yield at $800^{\circ} \mathrm{C}$ was reported. To eliminate or reduce heat and mass transfer limitations, approximately $7 \mathrm{mg}$ was used in alumina crucibles with a circular base $(6 \mathrm{~mm}$ in diameter and $3 \mathrm{~mm}$ in height, $70 \mu \mathrm{L}$ ) in each analysis. The accuracy of the TGA thermal balance is $0.001 \mathrm{mg}$.

The evolved gas was analyzed using an MS-QMID (mass spectroscopy with quasi multiple ion detection, QMID). Analysis to detect released ions was performed on a thermal balance (Netzsch, STA 449 F1 model), coupled to a quadrupole spectrometer mass (QMS 403 C Aëolos). Crude humins samples of approximately $10 \mathrm{mg}$ were placed in an $\mathrm{Al}_{2} \mathrm{O}_{3}$ crucible and the analysis was conducted at temperature range of $30-120^{\circ} \mathrm{C}$, heating rate of $15^{\circ} \mathrm{C} \cdot \mathrm{min}^{-1}$, with 20 minutes residence time at $120^{\circ} \mathrm{C}$. After the $120^{\circ} \mathrm{C}$ isotherm, the temperature was again rase to $800^{\circ} \mathrm{C}$ with heating rate of $15^{\circ} \mathrm{C} \mathrm{min}^{-1}$. The analysis was done under inert atmosphere $\left(\mathrm{N}_{2}\right)$, with gas flux of $50 \mathrm{~mL} \mathrm{~min}^{-1}$, and balance protective gas of $20 \mathrm{~mL} \mathrm{~min}^{-1}\left(\mathrm{~N}_{2}\right)$. The measuring module in mass spectrometer was set to scan bargraph module, $\mathrm{m} / \mathrm{z}$ range $10-100 \mathrm{amu}$, to continuously detect the ion currents from gaseous products; released during sample decomposition.

\subsubsection{Kinetics of the solid-state reaction}

The pyrolysis reaction of humins may be given as below:

$$
\text { Humins } \rightarrow \text { Volatiles }+ \text { Biochar }
$$

The thermogravimetric and kinetic behavior of the thermal/pyrolysis decomposition of humins were interpreted based on the mass loss profiles as a function of temperature and time, as well as the conversion. Therefore, the sample dehydration step was ignored, and the pyrolysis was analyzed in the interval of $150-800{ }^{\circ} \mathrm{C}$.

The conversion reaction rate is defined as:

$$
\frac{\mathrm{d} \alpha}{\mathrm{d} t}=k(T) f(\alpha)
$$

where $f(\alpha)$ is a mathematical function that represents the reaction mechanism (Table 1$)$, $k(T)$ is the conversion rate constant, and $\alpha$ is defined by Equation (6): 


$$
\alpha_{\exp }=\frac{W_{150}-W}{W_{150}-W_{800}} \quad\{\alpha: 0.150<\alpha<0.800\}
$$

where $W_{150}, W$, and $W_{800}$ are the normalized mass at $150{ }^{\circ} \mathrm{C}$, at a time $t$, and at $800{ }^{\circ} \mathrm{C}$, respectively.

$<T A B L E 1$ at the end of the manuscript $>$

The corresponding thermogravimetric conversion rate $(\mathrm{d} \alpha / \mathrm{d} t)$ is represented by Equation (7):

$$
\left(\frac{\mathrm{d} \alpha}{\mathrm{d} t}\right)_{\exp }=\frac{\mathrm{d} W}{\mathrm{~d} t}\left(\frac{1}{W_{800}-W_{150}}\right)
$$

The pyrolysis reaction kinetics is defined through the conversion rate presented by Equation (8):

$$
\left(\frac{\mathrm{d} \alpha}{\mathrm{dT}}\right)_{\text {calc }}=\frac{A}{\beta} \cdot f(\alpha) \cdot \exp \left(\frac{-E_{a}}{R T}\right)
$$

where $A$ is the pre-exponential factor $\left(\mathrm{min}^{-1}\right), E_{a}$ the activation energy $\left(\mathrm{kJ} \mathrm{mol}^{-1}\right), R$ is the universal gas constant $\left(8.3145 \mathrm{~J} \mathrm{~mol}^{-1} \mathrm{~K}^{-1}\right), T$ is the temperature $(\mathrm{K})$, and $\beta$ is the heating rate, which can be expressed by Equation (9):

$$
\frac{\mathrm{d} T}{\mathrm{~d} t}=\beta
$$

Equation (10) represents an integral form of Equation (8), where $g(\alpha)$ is the integral form of $f(\alpha), I\left(E_{a}, T\right)$ is the integral of temperature, without analytical solution, being commonly replaced by empirical approximations $(p(u))$, in which $u$ is defined as $E_{a} / R T$.

$$
g(\alpha)=\int_{0}^{\alpha} \frac{\mathrm{d} \alpha}{f(\alpha)}=\frac{A}{\beta} \int_{T_{o}}^{T} \exp \left(\frac{-E_{a}}{R T}\right) \mathrm{d} T \equiv \frac{A}{\beta} I\left(E_{a}, T\right)=\frac{A E_{a}}{\beta R} p(u)
$$

Table 1 presents different kinetic functions $f(\alpha)$ used to represent the pyrolysis reaction mechanisms and their respective integral forms $g(\alpha)$, such as kinetic mechanisms based on chemical reaction, one-dimensional and three-dimensional diffusion, nucleation and nuclei growth, and models based on phase boundary reactions [32]. 


\subsubsection{Isoconversional kinetic methods}

The thermogravimetric and kinetic behavior of non-catalytic pyrolysis of humins was evaluated using three isoconversional methods developed by Flynn-Wall-Ozawa (FWO) [33,34], Starink (STK) [35], and Vyazovkin (VYZ) [36].

The FWO method (Equation (11)) describes the reactions independent of the reaction rates and uses the linear Doyle approximation for the temperature integral [37].

$$
\ln \beta_{i}=\ln \left[\frac{A_{\alpha} E_{a_{\alpha}}}{R g(\alpha)}\right]-5.331-1.052 \frac{E_{a_{\alpha}}}{R T_{\alpha, i}}
$$

The STK method (Equation (12)) presents another approximation for the temperature integral, but it is considered more accurate when compared to the FWO method $[38,37]$.

$$
\ln \left(\frac{\beta_{i}}{T_{\alpha, i}{ }^{1.92}}\right)=\ln \left[\frac{R^{0.92} A_{\alpha}}{E_{a_{\alpha}}^{0.92} g(\alpha)}\right]-1.0008 \frac{E_{a_{\alpha}}}{R T_{\alpha, i}}
$$

The corresponding activation energy $E_{a \alpha}$ and the pre-exponential factor $A_{\alpha}$ can be found from the linear plots on the left-hand side of Equations (11) and (12) vs. $1 / T_{\alpha, i}$ in constant $\alpha$.

Because of simplified approximations in integral methods, Vyazovkin and Dollimore [36] developed the advanced nonlinear isoconversional method, using a revision of the method to express the temperature integral (Equation (13)). As the initial value for the optimization problem, the $E_{a \alpha}$ values determined with the FWO method were considered.

$$
\Omega\left(E_{a_{\alpha}}\right)=\min \left\{\begin{array}{l}
\sum_{i=1}^{n_{\alpha}=27} \sum_{j \neq i}^{n_{\alpha}=27} \frac{\beta_{j} I\left(E_{a_{\alpha}}, T_{\alpha, i}\right)}{\beta_{i} I\left(E_{a_{\alpha}}, T_{\alpha, j}\right)} \\
0.150 \leq \alpha \leq 0.800
\end{array}\right.
$$

The integral temperature of the VYZ method, $p(u)$, can be solved by means of numerical integration or using the approximation proposed by Pérez-Maqueda and Criado [39], presented in Equation (14).

$$
p(u)=\left[\frac{e^{-u}}{u}\right]\left(\frac{u^{7}+70 u^{6}+1886 x^{5}+24920 u^{4}+170136 u^{3}+577584 u^{2}+844560 u+357120}{u^{8}+72 u^{7} 2024 u^{6}+28560 u^{5}+216720 u^{4}+880320 u^{3}+1794240 u^{2}+1572480 u+403200}\right)
$$

\subsubsection{Determination of the kinetic mechanism}

Prediction of the kinetic behavior of the reaction was important to investigate the thermal/pyrolysis decomposition reaction mechanism, $f(\alpha)$. The most acceptable 
mechanism was determined using the master-plot method proposed by Criado [40] (Equation (15)), in which the master-plot $z(\alpha)$ was obtained by multiplying the differential and integral forms of the mechanisms described in Table 1, taking $\alpha=0.5$ as reference. These mechanisms were analyzed assuming in this study the thermogravimetric information related to the heating rate of $20^{\circ} \mathrm{C} \mathrm{min}^{-1}$.

$$
\frac{z(\alpha)}{z(0.5)}=\frac{f(\alpha) \times g(\alpha)}{f(0.5) \times g(0.5)}=\left(\frac{T_{\alpha}}{T_{0.5}}\right)^{2} \frac{(\mathrm{d} \alpha / \mathrm{d} T)_{\alpha}}{(\mathrm{d} \alpha / \mathrm{d} T)_{0.5}}
$$

where the right-hand side is known as the reduced conversion rate, calculated from the experimental data, and the left-hand side represents the theoretical master-plot. The quality of correspondence of this information was evaluated through the root mean square error. The choice of model was based on the curves that presented the best fit to the experimental data.

\subsubsection{Pre-Exponential factor estimation}

After the determination of the kinetic mechanism that most fairly represented the thermal degradation of humins, the pre-exponential factor $\left(A_{\alpha}\right)$ was estimated using the intercept obtained from the linear regressions of the linear methods presented in the Equations (11) and (12). For the VYZ method, Equation (8) was linearized based on the information obtained from the thermogravimetric study for this method, and the $\ln \left(A_{\alpha}\right)$ intercept was used as the initial value to estimate this parameter. By minimizing the root mean square error (Equation (16), with $\mathrm{N}=39$ ), parameter $A_{\alpha}$ was estimated by comparison of the experimental data of the conversion rate with the theoretical data obtained through Equation (8).

$$
R M S E=\sqrt{\frac{\sum_{j=1}^{N}\left[\left(\frac{\mathrm{d} \alpha}{\mathrm{dT}}\right)_{j, \text { experimental }}-\left(\frac{\mathrm{d} \alpha}{\mathrm{dT}}\right)_{j, \text { theoretical }}\right]^{2}}{N}}
$$




\subsubsection{Thermodynamic parameters}

The thermodynamic parameters were calculated using the fundamental theory of the activated complex [41]. The changes of enthalpy $(\Delta H)$, Gibbs free energy $(\Delta G)$, and entropy $(\Delta S)$ were calculated by the Equations (17)-(19).

$$
\begin{aligned}
& \Delta H_{\alpha}=E_{a_{\alpha}}-R T_{\alpha} \\
& \Delta G_{\alpha}=E_{a_{\alpha}}+R T_{m} \ln \left(K_{B} T_{m} / h A_{\alpha}\right) \\
& \Delta S_{\alpha}=\frac{\Delta H_{\alpha}-\Delta G_{\alpha}}{T_{m}}
\end{aligned}
$$

where $h$ is the Plank constant $\left(6.626 \times 10^{-34} \mathrm{~m}^{2} \mathrm{~kg} \mathrm{~s}^{-1}\right), K_{B}$ denotes Boltzmann constant $\left(1.381 \times 10^{-23} \mathrm{~m}^{2} \mathrm{~kg} \mathrm{~s}^{-2} \mathrm{~K}^{-1}\right)$, and $T_{m}$ is the maximum decomposition rate temperature.

\subsubsection{Data processing and management}

Experimental data were analyzed using the PAleontological STatistics (version 2.17c) and Microsoft Excel to perform the univariate statistical analysis and Tukey's test at a significance level of $p<0.05$. Thermoanalytical data, kinetic parameter estimation, and the one-step global single reaction modeling were carried out using Origin 8.1 (version v8. 0724) and Microsoft Excel. Vyazovkin's optimization approach in Equation (13) was solved using the Solver add-in of Microsoft Excel.

\section{Results and Discussion}

\subsection{Purification}

After the purification process, the yield of humins was $90.8 \pm 0.7 \%$ for $\mathrm{H}-\mathrm{SCB}$ and 95.7 $\pm 0.3 \%$ for $\mathrm{H}-\mathrm{RH}$. The results obtained in this work were similar to those reported by Song et al. [27] (92.5\%), thus indicating that the process for extraction of humins from soils is applicable for the purification of humins synthesized in biorefineries. This extraction method, using $\mathrm{NaOH}$, urea, DMSO, and $\mathrm{H}_{2} \mathrm{SO}_{4}$, achieves greater purification when compared to other processes that do not use sequential extraction because it removes aliphatic hydrocarbon structures, biomolecules such as carbohydrates and peptides, besides other lignin-derived structures. On the other hand, the water extraction process 
used in many other works $[42,43]$ removes only sugar derivatives and other hydrophilic compounds, as stated by Hoang et al. [44].

\subsection{Physicochemical characteristics}

The surface of humins consists of small, aggregated particles, with sizes between 1 and $6 \mu \mathrm{m}$ for $\mathrm{H}-\mathrm{SCB}$, and wide size distribution, between 1-10 $\mu \mathrm{m}$, for $\mathrm{H}-\mathrm{RH}$. In addition to the presence of these particles, it was observed that channels formed between them (Figure 1 (a)). These results are a characteristic aspect of humins and other carbonaceous solids. This size range is smaller than that of humins obtained from lignocellulosic biomass using $\mathrm{H}_{2} \mathrm{SO}_{4}$ as a catalyst, as described by Hoang et al. [45]. On the other hand, the particle size is relatively larger than that reported by Björnerbäck and Hedin [46] for humins derived from 5-hydroxymethylfurfural, which presented a size between 1-100 nm and a less spherical shape. The spherical morphology of $\mathrm{H}-\mathrm{SCB}$ and $\mathrm{H}-\mathrm{RH}$ also resembles the spherical particles obtained from glucose, but with a larger particle size distribution [18].

The functional groups of humins were analyzed using FT-IR and the spectra obtained are shown in Figure 1 (b). The spectra of both humins have similar absorbance patterns, but with different intensities, indicating that the humins had similar functional groups. The peak between 3420 and $3430 \mathrm{~cm}^{-1}$ is explained by the presence of hydroxyl groups [12,22], the peaks at $2920 \mathrm{~cm}^{-1}$ and $2950 \mathrm{~cm}^{-1}$ may indicate the presence of methyl and methylene structures [47,22], and the peak at $1710 \mathrm{~cm}^{-1}$ may belong to different groups such as aldehydes, ketones and esters $[48,12,45]$. Absorption observed between $1620 \mathrm{~cm}^{-}$

${ }^{1}$ and $1600 \mathrm{~cm}^{-1}$ may indicate the presence of amide groups [48]. The presence of furanic rings is observed at peaks between $1674 \mathrm{~cm}^{-1}$ and $1500 \mathrm{~cm}^{-1}$ for the $C=O$ and $C=C$ elongations [22,45]. Finally, CO elongation is observed between peaks 1284 and 1110 $\mathrm{cm}^{-1}$, representing alcohols and aliphatic ethers [22], while the peaks between 1000 and $800 \mathrm{~cm}^{-1}$ are an indication of out-of-plan $\mathrm{CH}$ attributed to substituted furans [18].

The proximate and ultimate analyses and the heating values of $\mathrm{H}-\mathrm{SCB}$ and $\mathrm{H}-\mathrm{RH}$ are presented in Table 2. The moisture content (less than 5\%) present in both humins is suitable for thermochemical processes involving the thermal decomposition of the 
material [49] because a higher moisture content can increase the sample dehydration step during the process and affect the yield of the formed products. Both humins have high volatile matter contents, thus helping in the regulation of thermal processes $[50,19]$. In addition, the high volatile matter content makes them suitable for the production of bio-liquids (e.g. pyrolysis bio-oil) and biogas [50], increases their ignition performance, and improves their heat release property [51]. Despite the statistically significant differences obtained in the immediate analysis, the high volatile matter, fixed carbon, and low moisture contents of both humins characterize these materials as suitable for thermal degradation processes.

\section{$<T A B L E 2$ available at the end of the manuscript $>$}

Elemental analysis is comparable with the existing literature on other humins synthesized from glucose [22] or in industrial processes [20,12]. Both H-SCB and H-RH presented a high $\mathrm{C}(\sim 60 \%)$ and $\mathrm{O}(\sim 29 \%)$ content and low $\mathrm{H}$ content $(\sim 4.7 \%)$ compared to other carbonaceous materials such as the products of hydrothermal carbonization of rice husk [48], miscanthus [23] e brewer's spent grains [52].

The high $\mathrm{H} / \mathrm{C}$ and $\mathrm{O} / \mathrm{C}$ atomic ratios (or degree of aromaticity) of $\mathrm{H}-\mathrm{SCB}$ indicate that its matrix has a greater amount of aliphatic bonds and oxygen groups compared to $\mathrm{H}$ $\mathrm{RH}$, as shown by the FTIR analysis (Figure $1(b)$ ), in which $\mathrm{H}-\mathrm{SCB}$ present sharper absorbance peaks in their spectrum. Also, the atomic ratios found for both $\mathrm{H}-\mathrm{SCB}$ and $\mathrm{H}-\mathrm{RH}$ indicate that they are more carbonaceous materials [52], making them comparable to lignite. The results are comparable to the atomic ratios obtained for humins synthesized from glucose $[20,22]$.

The high content of volatiles in $\mathrm{H}-\mathrm{SCB}$ led to a lower HHV $\left(22.45 \mathrm{MJ} \mathrm{kg}^{-1}\right)$ compared to $\mathrm{H}-\mathrm{RH}\left(24.70 \mathrm{MJ} \mathrm{kg}^{-1}\right)$ because the $\mathrm{H} / \mathrm{C}$ ratio and the $\mathrm{O} / \mathrm{C}$ ratio may lead to an increase in the energy content of the fuel. The high HHV values found are comparable to other carbonaceous materials $\left(21-31 \mathrm{MJ} \mathrm{kg}^{-1}\right)[52,19]$, making these humins attractive as renewable energy sources. 
The existence of structural differences of the investigated humins is observed through the empirical formulas $\mathrm{C}_{1.00} \mathrm{H}_{0.95} \mathrm{O}_{0.37}$ and $\mathrm{C}_{1.00} \mathrm{H}_{0.91} \mathrm{O}_{0.35}$ for $\mathrm{H}-\mathrm{SCB}$ and $\mathrm{H}-\mathrm{RH}$, respectively. Therefore, both humins are recognized as having good potential for thermochemical processes.

\subsection{Thermal/pyrolysis behavior analysis}

Thermogravimetric analyses were conducted in an $\mathrm{N}_{2}$ atmosphere using three heating rates to study the thermal decomposition of humins. Figure 2 (a) and (b) shows the normalized mass loss $(W)$ and normalized DTG $(d W / d t)$ curves for $\mathrm{H}-\mathrm{SCB}$ and $\mathrm{H}-\mathrm{RH}$. The investigation of species released during the mass loss stage of both humins is shown in Figure 2 (c) and (d). The thermal/pyrolysis decomposition of these humins can be divided into a dehydration process followed by pyrolysis, the latter being classified according to the transitions that occur in the process. Based on the DTG curves (Figure 2 (a) e (b)), the decomposition patterns under $\mathrm{N}_{2}$ can be classified into three regions. The first one is almost identical for both humins, characterizing the sample's dehydration process. In the DTG curves, the water loss of the samples is observed through a peak between the beginning of the process and $150^{\circ} \mathrm{C}$ and evidenced by peaks in MS of $m / z=17$ and $m / z=18$ (Figure 2 (c) and (d)). At this stage, it is possible to observe a loss of mass for H-SCB (Figure 2 (a)) of approximately $2.80 \%$ and for $\mathrm{H}$-RH (Figure 2 (b)) of approximately $4.60 \%$ for all heating rates. The behaviors observed in the mass loss and DTG profiles are similar between the different heating rates. From Figure 2 (d), it is observed the release of $\mathrm{CO}_{2}(m / z=48)$ and sulfur compounds $(m / z=44)$ for $\mathrm{H}-\mathrm{RH}$. The primary pyrolysis process is visualized in the degradation process presented in Figure 2 (a) e (b) in which there is a significant reduction in sample mass between $300{ }^{\circ} \mathrm{C}$ and 600 ${ }^{\circ} \mathrm{C}$. During this step, the $\mathrm{H}-\mathrm{SCB}$ and $\mathrm{H}-\mathrm{RH}$ lose approximately $26.49 \%$ and $21.43 \%$ in mass, respectively, around $400{ }^{\circ} \mathrm{C}$, caused by the release of volatile compounds and structural changes. Compared to the DTG curve for $\mathrm{H}-\mathrm{SCB}$, the DTG curve for $\mathrm{H}-\mathrm{RH}$ has a shoulder next to the main peak caused by the existence of other compounds formed during the biorefining (such as 5-hydroxymethylfurfural) which were not removed during the extraction process [20] or by breaking unstable structures in these humins [22]. It can 
be inferred that there is mainly the release in this step of compounds containing sulfur $(m / z=48$ and $m / z=64)$, hydrocarbons $(m / z=12)$, and $\mathrm{CO}_{2}(m / z=44)$.

The secondary decomposition stage occurs in the temperature range between 600 and $800{ }^{\circ} \mathrm{C}$, in which reactions such as dehydration and decarboxylation occur, with the decomposition of its structure at the same time [21]. Some condensation reactions and recombination of the formed fragments are possible [21] due to the slow degradation of non-carbonaceous and non-biodegradable residues [53] and by the degradation of high molecular weight molecules into aromatic compounds and formation of solid waste [54]; thus, the final biochar yield is about $42.37 \%$ for $\mathrm{H}-\mathrm{SCB}$ and $40.50 \%$ for $\mathrm{H}-\mathrm{RH}$. Yields were lower than those of humins that were obtained from glucose [22,20], suggesting that the thermal decomposition of $\mathrm{H}-\mathrm{SCB}$ and $\mathrm{H}-\mathrm{RH}$ tends to devolatilization instead of carbonization and consequently to a higher yield of gaseous and liquid products. On the other hand, the yield was close to that obtained in the pyrolysis of industrially obtained humins (44 \%) reported by Agarwal et al. [20], which have a high volatile content. Therefore, these conclusions highlight the results obtained through the immediate analysis of $\mathrm{H}-\mathrm{SCB}$ and $\mathrm{H}-\mathrm{RH}$, which indicated the tendency for biogas generation because of the moderate volatile matter content (57\% and $54 \%$, respectively).

There was an increase in biochar yield by increasing the heating rate, mostly observed in $\mathrm{H}-\mathrm{RH}$ sample. This phenomenon was also observed by Olszewski et al. [52] and, according to the authors, lower heating rates, as used in slow pyrolysis, increase the residence time of volatiles within the particles, resulting in a higher yield of biochar due to cracking, polymerization, and condensation reactions. The signals obtained in the MS of the two samples possibly reflect the statement made by the authors because there is the presence of signs referring to hydrocarbons and $\mathrm{CO}_{2}(\mathrm{~m} / \mathrm{z}=12$ and $\mathrm{m} / \mathrm{z}=44)$ at the end of the heating process for $\mathrm{H}-\mathrm{RH}$ while there is only the presence of signals referring to water loss in the process for H-SCB $(m / z=18)$, corroborating the earlier statement that humins have different structures.

The secondary thermal decomposition step is represented by a less accentuated mass loss when compared to the primary thermal/pyrolysis decomposition (Figure 2 (a) e (b)). On the other hand, when comparing the H-SCB and H-RH profiles, the behavior 
between these thermogravimetric profiles is different. There is a decrease in the speed of degradation only after $700^{\circ} \mathrm{C}$ and there is also a shoulder between $600{ }^{\circ} \mathrm{C}$ and 800 ${ }^{\circ} \mathrm{C}$, caused by the degradation of residual lignin from the biomass (which was not fully solubilized after the purification step).

The effect of the heating rate is visible in the DTG profiles because, with its increase, the peaks shift slightly to the right. This behavior is a consequence of the limitations of mass and heat transfer phenomena that cause temperature gradients among the surface and the interior of the sample and its particle [23]. Similarly, the increase in heating rates has significant effects on the release of volatile compounds, causing their increase. The DTG profiles indicated that thermal decomposition with the highest heating rate provides a higher decomposition rate and larger decomposition temperature ranges. Thus, it is likely that rapid warming could impose a faster rate of decomposition.

\subsection{Isoconversional kinetic study}

\subsubsection{The activation energy}

The thermal/pyrolysis decomposition kinetics of humins were calculated using the integral isoconversional methods. For the determination of the activation energy $\left(E_{a \alpha}\right)$, conversions between 0.150 and 0.800 and a step equal to 0.025 were adopted as the study interval, covering the interval with determination factors greater than 0.7 .

The linear fits of the STK and FWO methods in the studied conversion interval are shown in Figure 3. The activation energy calculated for each method varying the conversion is shown in Table 3. The linear integral methods present a uniform behavior (Figure 3), which is an expected result of these methods because they are directly based on the reaction rate data. As can be seen from Table 3, there is a low variation in the activation energy for $\mathrm{H}-\mathrm{SCB}$ from the beginning of the studied conversion interval up to $\alpha=0.450$, for all studied methods, between 5.70 to $6.30 \mathrm{~kJ} \mathrm{~mol}^{-1}$ approximately. The conversion of 0.425 corresponds to a temperature close to $400{ }^{\circ} \mathrm{C}$, which corresponds to the peak observed in the DTG related to the maximum decomposition of organic matter and release of volatile components. Therefore, the primary thermal decomposition step occurs stably and with an energy of activation between 165 and $175 \mathrm{~kJ} \mathrm{~mol}^{-1}$. After a 
conversion of 0.425 , there is an increase in the activation energy for the FWO, STK, and VYZ methods. This trend was also observed by Bartocci et al. [55] between the range of conversions from 0.050 to 0.550 but followed by a drop until the end of the reaction. Sobek and Werle [56] stated that the increase in activation energy observed was the result of highly endothermic carbonization reactions, comprising the interval of secondary pyrolysis and biochar formation. Furthermore, Sangregorio et al. [25] stated that this behavior was due to the increased mobility of long-chain compounds that promoted the reactivation of chemical reactions.

$<T A B L E 3$ is available at the end of the manuscript $>$

Similarly, it was observed for $\mathrm{H}-\mathrm{RH}$ a variation between 3.89 and $4.5 \mathrm{~kJ} \mathrm{~mol}^{-1}$ in the $E_{a \alpha}$ from the conversion of 0.175 to 0.300 for all methods, corresponding to the peak observed in the DTG between 354 and $370{ }^{\circ} \mathrm{C}$ related to the maximum decomposition of organic matter and release of volatile components, thus indicating that the primary thermal decomposition step also occurs stably. After this conversion interval, the activation energy increases in all methods until the conversion of 0.475 , reaching a maximum between 234.79 and $237.28 \mathrm{~kJ} \mathrm{~mol}^{-1}$. This conversion interval corresponds to the shoulder located close to the main peak. The reduction in the activation energy after the conversion of 0.525 is an indication of the decomposition of thermally unstable structures and the reduction in the mobility of short-chain compounds due to diffusion limitations [25].

The results show the dependence of activation energy on the conversion is a strong indication that thermal/pyrolysis decomposition does not occur in a single step, but rather in multiple steps, which is in agreement with previous results from Vyazovkin et al. [38]. Such behavior has also been observed in other works referring to the thermal decomposition of residues from anaerobic reactions [55], rice husks [48], and brewing residues [52].

The average kinetic parameters (Table 3) have the same order of magnitude and their differences can be explained by the way the methods are structured, that is, FWO and 
STK use simplifications in their constructions while VYZ is solved through optimization procedures. The behavior observed for the two humins indicates the occurrence of at least two reactions occurring in sequence [55].

$\mathrm{H}-\mathrm{SCB}$ humins have higher average activation energy $\left(\sim 210 \mathrm{~kJ} \mathrm{~mol}^{-1}\right)$ compared to $\mathrm{H}-\mathrm{RH}\left(\sim 185 \mathrm{~kJ} \mathrm{~mol}^{-1}\right)$. This fact demonstrates that these humins are more thermally stable. The activation energy obtained is higher, but comparable to those reported in the literature for humins synthesized from xylose and glucose $\left(150 \mathrm{~kJ} \mathrm{~mol}^{-1}\right.$ and $163 \mathrm{~kJ} \mathrm{~mol}^{-}$ 1 , respectively [22]), explained by the biomass source used for the synthesis of humins and the biorefining process.

\subsubsection{Elucidating the kinetic mechanism}

The master-plot curves (Figure 4) were determined by using the mean activation energy from the isoconversion methods with thermoanalytical data $(d \alpha / d t$ kinetic curves and temperature profiles) at $20^{\circ} \mathrm{C} \mathrm{min}^{-1}$. The reaction mechanism is established based on the best experimental fit to the functions in Table 1 according to the RMSE. The VYZ method is the method that best describes the pyrolysis of the studied humins considering the determination factor obtained (mean $\mathrm{R}^{2}$ of 0.992 and 0.977 for $\mathrm{H}-\mathrm{SCB}$ and $\mathrm{H}-\mathrm{RH}$, respectively, presented in Table 3) and for being the method that presents greater accuracy compared to integral methods. Table 4 presents the RMSE found for all the mechanism functions (Table 1) for the VYZ method and only the most likely reaction models for the VYZ method (marked with $a^{\prime \prime \prime}$ in Table 4) were plotted in Figure 4. The RMSE values for the other isoconversional methods are shown in the supplementary material.

\section{$<T A B L E 4$ available at the end of the manuscript $>$}

The results showed that the thermal/pyrolysis decomposition of $\mathrm{H}-\mathrm{SCB}$ obeyed the chemical reaction mechanisms $\left(F_{3 / 2}, F_{2}, F_{3}\right.$, and $\left.F_{4}\right)$ because of the low RMSE (between 0.149 and 0.220 ), in addition to the three-dimensional diffusion mechanism $\left(D_{5}\right)$ and nucleation described by exponential law $\left(E_{1}\right)$. Comparing the obtained curves, the 
Avrami-Erofeev random nucleation ( $A_{n}$ models) and three-dimensional diffusion $\left(D_{3}, D_{4}\right.$, and $D_{5}$ ) mechanisms showed greater numerical correspondence with the experimental data from the VYZ method up to a conversion of 0.300 , while the mechanisms of second and third-order chemical reaction ( $F_{2}$ and $F_{3}$, respectively) showed better correspondence up to a conversion of 0.500 . It is noteworthy that the nucleation mechanisms described by exponential $\left(E_{1}\right.$ and $\left.E_{2}\right)$ and chemical reaction $\left(F_{4}\right)$ laws showed similar behavior after conversion of 0.500 .

Similarly, the thermal/pyrolysis decomposition of $\mathrm{H}-\mathrm{RH}$ obeyed the chemical reaction mechanisms $\left(F_{3 / 4}, F_{3 / 2}, F_{2}\right.$, and $\left.F_{3}\right)$ also because of the low RMSE (0.131-0.211), in addition to the reaction mechanisms in the boundary layer $\left(R_{2}\right.$ and $\left.R_{3}\right)$ and three-dimensional diffusion $\left(D_{3}\right.$ and $\left.D_{5}\right)$. It was observed that a phase boundary-controlled reaction described by a one-dimensional diffusion mechanism $\left(D_{1}\right)$ exists up to a conversion of 0.500 , followed by three-dimensional diffusion reactions $\left(D_{5}\right)$, nucleation $\left(E_{1}\right)$, and chemical reaction $\left(F_{3}\right.$ and $\left.F_{4}\right)$ for conversion between 0.300 and 0.700 . Finally, the final step of thermal decomposition can be represented by one-dimensional boundary layer reactions $\left(R_{1} / F_{0}\right)$.

The diffusion mechanisms that described the pyrolysis of both humins (such as the $D_{5}$ model presented in Equation (20)) are characterized by deceleration kinetics, that is, the conversion reaches an upper limit at the beginning of the thermal/pyrolysis decomposition and then reduces as the conversion increases [38]

$$
f(\alpha)=3 / 2(1-\alpha)^{4 / 3}\left[(1-\alpha)^{-1 / 3}-1\right]^{-1}
$$

Chemical reaction models or models based on the order of reaction (model $F_{3 / 2}$ presented in Equation (21)) are also characterized by deceleration kinetics and are simpler and more practical [38]. In this model, the kinetic rate is directly proportional to the concentration change of unreacted material raised at a given power [38]. It is frequently used in thermal analysis studies due to its simplicity.

$$
f(\alpha)=2(1-\alpha)^{3 / 2}
$$

Nucleation models describe the formation of a new product phase at nucleation sites within the reagent array and can occur in one $\left(E_{1}\right.$ model) or multiple steps ( $P_{1 / 2}$ model 
described in Equation (22)). Furthermore, when nucleation occurs in multiple stages, the nuclei are classified as germinated nuclei, where the product particles can revert to reactants and growth nuclei in which the reaction normally takes place.

$$
f(\alpha)=2 \alpha^{1 / 2}
$$

The results observed are consistent with the phenomena that occur during pyrolysis and with reports referring to pyrolysis of algal biomass [57] or waste wood [56] and acid hydrolysis residue of miscanthus [23]. The pyrolysis process of humins was mostly associated with diffusion reactions (conversion interval between $0.15-0.30$ ) because the reaction occurs between the solid phase and gas and in conversions near the end of the reaction when the formation of biochar occurs. At this stage, the reaction propagates from the external surface of the biochar to its interior [57]. The occurrence of nuclei growth reactions can be justified by the occurrence of defects in the structure of humins that act as nucleation sites [57].

Especially, the fact that more than one kinetic mechanism can represent the studied processes corroborates the hypothesis pointed out in the previous sections that pyrolysis is a complex process that occurs in multiple stages. Thus, it becomes necessary a multiple reactions approach, that is, considering that the thermal/pyrolysis decomposition of humins is characterized by overlapping reactions (parallel independent and consecutive reactions), which will be developed in further studies for a better description of the thermal degradation of humins.

\subsubsection{Estimating the pre-exponential factor}

Based on the kinetic model that best described the thermal decomposition of humins, the pre-exponential factor $\left(A_{\alpha}\right)$ was determined by minimizing Equation (16) using the selected heating rates and the conversion range between 0.150 and 0.800 . As a result, we obtained a parameter equal to $2.343 \times 10^{13} \mathrm{~min}^{-1}$ for $\mathrm{H}-\mathrm{SCB}$ and $7.467 \times 10^{10} \mathrm{~min}^{-1}$ for $\mathrm{H}-\mathrm{RH}$. The pre-exponential factor found for the one-step global single reaction of $\mathrm{H}-\mathrm{SCB}$ and $\mathrm{H}-\mathrm{RH}$ indicates that fewer molecular collisions are required for the generation of active complexes $[49,53]$. 


\subsubsection{Thermodynamic parameters}

The feasibility of the process was also evaluated through thermodynamic parameters. The mean activation energy values computed from the VYZ method were utilized to evaluate the thermodynamic parameters within a certain conversion range $(0.150<\alpha<0.800)$.

The enthalpy change $\left(\Delta H_{\alpha}\right)$ demonstrates the total energy consumption by humins in the thermal/pyrolysis decomposition for the formation of products [53]. Positive changes, such as those found for H-SCB and H-CA (Figure 5 (a) and (d)), demonstrate that decomposition is an endothermic process. It is observed that the $\Delta H_{\alpha}$ for $\mathrm{H}$-SCB slightly varies from the beginning of the process until the conversion of approximately 0.425 , indicating that the primary pyrolysis step occurs stably. Then, there is an increase in $\Delta H_{\alpha}$ after this conversion, showing that there is a greater need for energy to convert parts of the humins not yet reacted into activated complexes [57].

As for $\mathrm{H}-\mathrm{RH}$, there is an increase in $\Delta H_{\alpha}$ up to the conversion of approximately 0.500 that indicates that more energy is needed to convert this humin into products, in addition to this process occurring in two or more stages, explained by the existence of the shoulder next to the major degradation peak or maximum decomposition rate. After the conversion of 0.500 , there is a reduction in $\Delta H_{\alpha}$ that indicates the decrease of the endothermic behavior of the process.

The small differences between activation energy and $\Delta H_{\alpha}\left(\sim 6 \mathrm{~kJ} \mathrm{~mol}^{-1}\right)$ demonstrate that the energy potential barrier required for the production of the activated complex to form the products is easily overcome $[49,53]$, indicating that the formation of the products is favorable [49].

Not only is the disorder of the system determined by the entropy change $\left(\Delta S_{\alpha}\right)$ but also how reactive the process is. In thermal degradations, $\Delta S_{\alpha}$ indicates that the thermochemical equilibrium was reached and a thermally stable product was formed [49]. In comparison among the studied humins, it is inferred that $\mathrm{H}-\mathrm{SCB}$ has greater reactivity compared to $\mathrm{H}-\mathrm{RH}$ because it has higher $\Delta S_{\alpha}$ (Figure 5 (b) e (e)), suggesting that this material will take a shorter time to form the activated complex $[49,53]$. For both 
humins, it was observed that $\Delta S_{\alpha}$ decreases with increasing conversion (Figure 5 (b) e (e)), indicating a gradual drop in reactivity.

Finally, the Gibbs free energy change $\left(\Delta G_{\alpha}\right)$ indicates the amount of energy supplied to a material during the thermal process. Analogously to what was observed in $\Delta H_{\alpha_{1}}$ the primary pyrolysis step of $\mathrm{H}-\mathrm{SCB}$ occurs stably (Figure 5 (b)), requiring almost the same amount of energy, and after the conversion of 0.425 , part of the energy supplied to the system was a surplus. On the other hand, for $\mathrm{H}-\mathrm{RH}$ (Figure $5(\mathrm{e})$ ), it can be inferred that a greater amount of energy had to be supplied to the system for the process to happen [49] up to a conversion of 0.5 ; then, the decrease indicates that less energy was needed for the process to continue.

\subsubsection{Assessment of the one-step global single reaction}

Figure 6 presents the theoretical and experimental conversion rates obtained for the thermal decomposition of $\mathrm{H}-\mathrm{SCB}$ and $\mathrm{H}-\mathrm{RH}$, assuming a global reaction model and three heating rates. Theoretical calculations were performed using the kinetic mechanism function established with the generalized master-plot method and kinetic parameters obtained from the VYZ method. Theoretical curves represent the experimental data well with a good fit, showing RMSE in the order of $10^{-19}$ for $\mathrm{H}-\mathrm{SCB}$ and $10^{-18}$ for $\mathrm{H}-\mathrm{RH}$.

The achieved results improve the understanding of the mechanisms of thermal/pyrolysis decomposition of humins, in addition to serving as initial estimates for other processes that work with humins from other sources or carbonaceous materials.

\section{Conclusions}

This work showed that humins from a three-step biorefining of sugarcane bagasse $(\mathrm{H}-\mathrm{SCB})$ and rice husk $(\mathrm{H}-\mathrm{RH})$ have similar spherical morphology. The potential use of $\mathrm{H}$ $\mathrm{SCB}$ and $\mathrm{H}-\mathrm{RH}$ as solid fuels was confirmed by the high $\mathrm{O} / \mathrm{C}(>0.35)$ and $\mathrm{H} / \mathrm{C}(>0.91)$ atomic ratios and high carbon content (60\%). Thermogravimetric decomposition profiles showed three main steps in the conversion: dehydration of the samples, followed by a severe mass loss due to the release of volatile organic compounds, and the formation of biochar. Based on kinetic analysis, the average activation energies calculated by the 
Starinki (STK) and Flynn-Wall-Ozawa (FWO) isoconversional methods and the nonlinear Vyazovkin method (VYZ) were $211.53 \mathrm{~kJ} \mathrm{~mol}^{-1}$ for $\mathrm{H}-\mathrm{SCB}$ and $184.30 \mathrm{~kJ} \mathrm{~mol}^{-1} \mathrm{H}-\mathrm{RH}$. The mechanisms that best described the decomposition of both humins were order-based models and three-dimensional diffusion, in addition to the nucleation mechanism for $\mathrm{H}$ $\mathrm{SCB}$ and boundary layer reaction for $\mathrm{H}-\mathrm{RH}$. Analysis of thermodynamic data showed that $\mathrm{H}-\mathrm{SCB}$ is more reactive than $\mathrm{H}-\mathrm{RH}$. As interest grows in the processing of biomass into levulinic acid, there will be greater production of humins. Therefore, the information presented in this work allows further research on the applications of byproducts of biorefineries.

\section{Acknowledgments}

The authors would like to thank Centro de Equipamentos e Serviços Multiusuários CESM (Institute of Environmental, Chemical and Pharmaceutical Sciences at Federal University of São Paulo) for the support with TGA and the Laboratory of Recycling, Waste Treatment and Extraction - LAREX (Department of Chemical Engineering, Escola Politécnica of the University of São Paulo) for the support with TG-QMS.

\section{Funding Information}

This work was supported by National Council for Scientific and Technological Development - CNPq [grants 408149/2018-3 and 162373/2020-1] and São Paulo Research Foundation - FAPESP [grants 2020/11347-5, 2015/17592-3, and 2015/206304].

\section{Conflicts of interest/Competing interests}

The authors declare that they have no conflict of interest.

\section{Ethics approval}

Registers CEP N 6389190320, 2804210420 and 5800140620 by Comitê de Ética em Pesquisa da Universidade Federal de São Paulo/Hospital São Paulo. 


\section{Availability of data and material}

E-supplementary information for this work can be found in e-version of this paper online.

\section{Code availability}

Not applicable.

\section{Author Contribution Statement}

Julio César de Jesus Gariboti: conceptualization, methodology (kinetic analysis), validation, formal analysis, data curation, writing - original draft; Marina Gontijo Souza Macedo: conceptualization, methodology (purification and physicochemical characteristics), data curation, writing - original draft; Vinícius Matheus Silva Macedo: methodology (purification and physicochemical characteristics), Yesid Javier Rueda: conceptualization, validation (kinetic analysis), writing- reviewing and editing; Emília Savioli Lopes: methodology (production of agro-industrial acid hydrolysis residue); Jonathan Tenorio Vinhal: Methodology (TG-QMS analysis), validation, writing - original draft, Eliezer Ladeia Gomes: conceptualization, validation, writing - original draft, supervision; Jorge Alberto Soares Tenório: validation, writing - reviewing and editing; Romilda Fernandez Felisbino: validation, writing - original draft, supervision; Melina Savioli Lopes: conceptualization, validation (thermodynamic analysis), writing- reviewing and editing; Laura Plazas Tovar: conceptualization, validation, writing - original draft, writing - reviewing and editing, resources, visualization, supervision, funding acquisition and project administration.

\section{References}

1. Keijer T, Bakker V, Slootweg JC (2019) Circular chemistry to enable a circular economy. Nature chemistry 11 (3):190-195. doi:https://doi.org/10.1038/s41557-019-0226-9

2. Lopes ES, Leal Silva JF, Rivera EC, Gomes AP, Lopes MS, Maciel Filho R, Tovar LP (2020) Challenges to levulinic acid and humins valuation in the sugarcane bagasse biorefinery concept. BioEnergy Research 13 (3):757-774. doi:https://doi.org/10.1007/s12155-020$\underline{10124-9}$

3. Lopes ES, Gariboti JCJ, Feistel L, Rivera EC, Maciel Filho R, Tovar LP (2020) Acid Hydrolysis-based Sugarcane Bagasse Biorefining for Levulinic Acid Production: Dynamic 
Mechanistic Modeling Under Varying Operating Conditions. Chemical Engineering Transactions 80:217-222. doi:https://doi.org/10.3303/CET2080037

4. Lopes ES, Rivera EC, Gariboti JCdJ, Feistel LHZ, Dutra JV, Maciel Filho R, Tovar LP (2020) Kinetic insights into the lignocellulosic biomass-based levulinic acid production by a mechanistic model. Cellulose 27 (10):5641-5663. doi:https://doi.org/10.1007/s10570020-03183-w

5. Fleig OP, Lopes ES, Rivera EC, Maciel Filho R, Tovar LP (2018) Concept of rice husk biorefining for levulinic acid production integrating three steps: Multi-response optimization, new perceptions and limitations. Process Biochemistry 65:146-156. doi:https://doi.org/10.1016/j.procbio.2017.11.015

6. Leal Silva JF, Mariano AP, Maciel Filho R (2021) Less severe reaction conditions to produce levulinic acid with reduced humins formation at the expense of lower biomass conversion: Is it economically feasible? Fuel Communications 9:100029. doi:https://doi.org/10.1016/j.jueco.2021.100029

7. Kang S, Fu J, Zhang G (2018) From lignocellulosic biomass to levulinic acid: A review on acid-catalyzed hydrolysis. Renewable and Sustainable Energy Reviews 94:340-362. doi:https://doi.org/10.1016/j.rser.2018.06.016

8. Shao Y, Lu W, Meng Y, Zhou D, Zhou Y, Shen D, Long Y (2021) The formation of 5hydroxymethylfurfural and hydrochar during the valorization of biomass using a microwave hydrothermal method. Science of The Total Environment 755:142499. doi:https://doi.org/10.1016/j.scitotenv.2020.142499

9. Macedo MGS, Gariboti JCJ, Lopes ES, Gomes EL, Felisbino RF, Ardila YC, Tovar LP From sugarcane bagasse-derived humins towards porous materials with high-energy potential. 43rd Symposium on Biomaterials, Fuels

and Chemicals, Virtual Conference, ate 2021.

10. Muralidhara A, Tosi P, Mija A, Sbirrazzuoli N, Len C, Engelen V, de Jong E, Marlair G (2018) Insights on thermal and fire hazards of humins in support of their sustainable use in advanced biorefineries. ACS Sustainable Chemistry \& Engineering 6 (12):16692-16701. doi:https://doi.org/10.1021/acssuschemeng.8b03971

11. Higgins LJR, Brown AP, Harrington JP, Ross AB, Kaulich B, Mishra B (2020) Evidence for a core-shell structure of hydrothermal carbon. Carbon 161:423-431. doi:https://doi.org/10.1016/j.carbon.2020.01.060

12. Tosi P, van Klink GPM, Celzard A, Fierro V, Vincent L, de Jong E, Mija A (2018) Autocrosslinked rigid foams derived from biorefinery byproducts. ChemSusChem 11 (16):2797-2809. doi:https://doi.org/10.1002/cssc.201800778

13. Dinu R, Mija A (2019) Cross-linked polyfuran networks with elastomeric behaviour based on humins biorefinery by-products. Green Chemistry 21 (23):6277-6289. doi:https://doi.org/10.1039/C9GC01813A

14. Yang J, Niu X, Wu H, Zhang H, Ao Z, Zhang S (2020) Valorization of humin as a glucose derivative to fabricate a porous carbon catalyst for esterification and hydroxyalkylation/alkylation. Waste Management 103:407-415. doi:https://doi.org/10.1016/j.wasman.2020.01.004

15. Dinu R, Montes S, Orange F, Mija A (2021) Reprocessable humins thermosets and composites. Composites Science and Technology 207:108655. doi:https://doi.org/10.1016/j.compscitech.2021.108655 
16. Sun J, Cheng H, Zhang Y, Zhang Y, Lan X, Zhang Y, Xia Q, Ding D (2021) Catalytic hydrotreatment of humins into cyclic hydrocarbons over solid acid supported metal catalysts in cyclohexane. Journal of Energy Chemistry 53:329-339. doi:https://doi.org/10.1016/j.jechem.2020.05.034

17. Morone A, Apte M, Pandey RA (2015) Levulinic acid production from renewable waste resources: Bottlenecks, potential remedies, advancements and applications. Renewable and Sustainable Energy Reviews 51:548-565. doi:https://doi.org/10.1016/j.rser.2015.06.032

18. van Zandvoort I, Wang $Y$, Rasrendra $C B$, van Eck ERH, Bruijnincx PCA, Heeres $H J$, Weckhuysen BM (2013) Formation, molecular structure, and morphology of humins in biomass conversion: influence of feedstock and processing conditions. ChemSusChem 6 (9):1745-1758. doi:https://doi.org/10.1002/cssc.201300332

19. Magdziarz A, Wilk M, Wądrzyk M (2020) Pyrolysis of hydrochar derived from biomass - Experimental investigation. Fuel 267:117246. doi:https://doi.org/10.1016/j.fuel.2020.117246

20. Agarwal S, van Es D, Heeres HJ (2017) Catalytic pyrolysis of recalcitrant, insoluble humin byproducts from $\mathrm{C} 6$ sugar biorefineries. Journal of Analytical and Applied Pyrolysis 123:134-143. doi:https://doi.org/10.1016/j.jaap.2016.12.014

21. Mija A, van der Waal JC, Pin J-M, Guigo N, de Jong E (2017) Humins as promising material for producing sustainable carbohydrate-derived building materials. Construction and Building Materials 139:594-601. doi:https://doi.org/10.1016/j.conbuildmat.2016.11.019

22. Wang S, Lin H, Zhao Y, Chen J, Zhou J (2016) Structural characterization and pyrolysis behavior of humin by-products from the acid-catalyzed conversion of $\mathrm{C} 6$ and $\mathrm{C} 5$ carbohydrates. Journal of Analytical and Applied Pyrolysis 118:259-266. doi:https://doi.org/10.1016/j.jaap.2016.02.009

23. Cortés AM, Bridgwater AV (2015) Kinetic study of the pyrolysis of miscanthus and its acid hydrolysis residue by thermogravimetric analysis. Fuel Processing Technology 138:184-193. doi:https://doi.org/10.1016/j.fuproc.2015.05.013

24. Sbirrazzuoli N (2020) Interpretation and physical meaning of kinetic parameters obtained from isoconversional kinetic analysis of polymers. Polymers (Basel) 12 (6):1280. doi:https://doi.org/doi:10.3390/polym12061280

25. Sangregorio A, Guigo N, Jong Ed, Sbirrazzuoli N (2019) Kinetics and chemorheological analysis of cross-linking reactions in humins. Polymers (Basel) 11 (11):1804. doi:https://doi.org/doi:10.3390/polym11111804

26. Chang RR, Mylotte R, Hayes MHB, McLnerney R, Tzou YM (2014) A comparison of the compositional differences between humic fractions isolated by the IHSS and exhaustive $\begin{array}{llll}\text { extraction } & \text { procedures. } \quad \text { Naturwissenschaften } & 101 & \text { (3):197-209. }\end{array}$ doi:https://doi.org/10.1007/s00114-013-1140-4

27. Song G, Novotny E, Simpson A, Clapp CE, Hayes MHB (2008) Sequential exhaustive extraction of a Mollisol soil, and characterizations of humic components, including humin, by solid and solution state NMR. European Journal of Soil Science 59:505-516. doi:https://doi.org/10.1111/j.1365-2389.2007.01006.x

28. American Society for Testing and Materials (2017). ASTM D3173 / D3173M-17a, Standard test method for moisture in the analysis sample of coal and coke. American 
Society for Testing and Materials, West Conshohocken, PA. doi:https://doi.org/10.1520/D3173 D3173M-17A

29. American Society for Testing and Materials (2018). ASTM D3174-02, Standard test method for ash in the analysis sample of coal and coke from coal. American Society for Testing and Materials, West Conshohocken, PA. doi:https://doi.org/10.1520/D3174$12 \mathrm{R} 18$

30. American Society for Testing and Materials (2020). ASTM D3175-20, Standard test method for volatile matter in the analysis sample of coal and coke. American Society for Testing and Materials, West Conshohocken, PA. doi:https://doi.org/10.1520/D3175-20 31. Nhuchhen DR (2016) Prediction of carbon, hydrogen, and oxygen compositions of raw and torrefied biomass using proximate analysis. Fuel 180:348-356. doi:https://doi.org/10.1016/j.fuel.2016.04.058

32. Trache D, Abdelaziz A, Siouani B (2016) A simple and linear isoconversional method to determine the pre-exponential factors and the mathematical reaction mechanism functions. Journal of Thermal Analysis and Calorimetry. doi:https://doi.org/10.1007/s10973-016-5962-0

33. Ozawa T (1965) A new method of analyzing thermogravimetric data. Bulletin of the Chemical Society of Japan 38 (11):1881-1886. doi:https://doi.org/10.1246/bcsj.38.1881

34. Flynn JH, Wall LA (1966) General treatment of the thermogravimetry of polymers. J Res Natl Bur Stand A Phys Chem 70A (6):487-523. doi:https://doi.org/10.6028/jres.070A.043

35. Starink MJ (2003) The determination of activation energy from linear heating rate experiments: a comparison of the accuracy of isoconversion methods. Thermochimica Acta 404 (1):163-176. doi:https://doi.org/10.1016/S0040-6031(03)00144-8

36. Vyazovkin S, Dollimore D (1996) Linear and nonlinear procedures in isoconversional computations of the activation energy of nonisothermal reactions in solids. Journal of Chemical Information and Computer Sciences 36 (1):42-45. doi:https://doi.org/10.1021/ci950062m

37. Balart R, Garcia-Sanoguera D, Quiles-Carrillo L, Montanes N, Torres-Giner S (2019) Kinetic analysis of the thermal degradation of recycled acrylonitrile-butadiene-styrene by non-isothermal thermogravimetry. Polymers (Basel) 11 (2). doi:https://doi.org/10.3390/polym11020281

38. Vyazovkin S, Burnham AK, Criado JM, Pérez-Maqueda LA, Popescu C, Sbirrazzuoli N (2011) ICTAC kinetics committee recommendations for performing kinetic computations on thermal analysis data. Thermochimica Acta 520 (1):1-19. doi:https://doi.org/10.1016/j.tca.2011.03.034

39. Pérez-Maqueda LA, Criado JM (2000) The accuracy of Senum and Yang's approximations to the Arrhenius integral. Journal of Thermal Analysis and Calorimetry 60 (3):909-915. doi:https://doi.org/10.1023/A:1010115926340

40. Criado JM (1978) Kinetic analysis of DTG data from master curves. Thermochimica Acta 24 (1):186-189. doi:https://doi.org/10.1016/0040-6031(78)85151-X

41. Eyring $H$ (1935) The activated complex in chemical reactions. The Journal of Chemical Physics 3:107. doi:https://doi.org/10.1063/1.1749604 
42. Sumerskii IV, Krutov SM, Zarubin MY (2010) Humin-like substances formed under the conditions of industrial hydrolysis of wood. Russian Journal of Applied Chemistry 83 (2):320-327. doi:https://doi.org/10.1134/S1070427210020266

43. Cheng Z, Everhart JL, Tsilomelekis G, Nikolakis V, Saha B, Vlachos DG (2018) Structural analysis of humins formed in the Brønsted acid catalyzed dehydration of fructose. Green Chemistry 20 (5):997-1006. doi:https://doi.org/10.1039/C7GC03054A

44. Hoang TMC, Lefferts L, Seshan K (2013) Valorization of humin-based nyproducts from biomass processing —A Route to sustainable hydrogen. ChemSusChem 6 (9):1651-1658. doi:https://doi.org/10.1002/cssc.201300446

45. Hoang TMC, van Eck ERH, Bula WP, Gardeniers JGE, Lefferts L, Seshan K (2015) Humin based by-products from biomass processing as a potential carbonaceous source for synthesis gas production. Green Chemistry $17 \quad$ (2):959-972. doi:https://doi.org/10.1039/C4GC01324G

46. Björnerbäck F, Hedin N (2019) Microporous humins prepared from sugars and biobased polymers in concentrated sulfuric acid. ACS Sustainable Chemistry \& Engineering 7 (1):1018-1027. doi:https://doi.org/10.1021/acssuschemeng.8b04658

47. Alves JLF, Da Silva JCG, da Silva Filho VF, Alves RF, de Araujo Galdino WV, Andersen SLF, De Sena RF (2019) Determination of the bioenergy potential of brazilian pine-fruit shell via pyrolysis kinetics, thermodynamic study, and evolved gas analysis. BioEnergy Research 12 (1):168-183. doi:https://doi.org/10.1007/s12155-019-9964-1

48. Zhang S, Pi M, Su Y, Xu D, Xiong Y, Zhang H (2020) Physiochemical properties and pyrolysis behavior evaluations of hydrochar from co-hydrothermal treatment of rice straw and sewage sludge. Biomass and Bioenergy 140:105664. doi:https://doi.org/10.1016/j.biombioe.2020.105664

49. Shahid A, Ishfaq M, Ahmad MS, Malik S, Farooq M, Hui Z, Batawi AH, Shafi ME, Aloqbi AA, Gull M, Mehmood MA (2019) Bioenergy potential of the residual microalgal biomass produced in city wastewater assessed through pyrolysis, kinetics and thermodynamics study to design algal biorefinery. Bioresource Technology 289:121701. doi:https://doi.org/10.1016/j.biortech.2019.121701

50. Radojević M, Janković B, Jovanović V, Stojiljković D, Manić N (2018) Comparative pyrolysis kinetics of various biomasses based on model-free and DAEM approaches improved with numerical optimization procedure. PLOS ONE 13 (10):e0206657. doi:https://doi.org/10.1371/journal.pone.0206657

51. Wang Y, Qiu L, Zhu M, Sun G, Zhang T, Kang K (2019) Comparative evaluation of hydrothermal carbonization and low temperature pyrolysis of Eucommia ulmoides oliver for the production of solid biofuel. Scientific Reports 9 (1):5535. doi:https://doi.org/10.1038/s41598-019-38849-4

52. Olszewski MP, Arauzo PJ, Maziarka PA, Ronsse F, Kruse A (2019) Pyrolysis kinetics of hydrochars produced from brewer's spent grains. Catalysts 9 (7):625. doi:https://doi.org/doi:10.3390/catal9070625

53. Ma J, Luo H, Li Y, Liu Z, Li D, Gai C, Jiao W (2019) Pyrolysis kinetics and thermodynamic parameters of the hydrochars derived from co-hydrothermal carbonization of sawdust and sewage sludge using thermogravimetric analysis. Bioresource Technology 282:133141. doi:https://doi.org/10.1016/j.biortech.2019.03.007 
54. Zeng K, Gauthier D, Soria J, Mazza G, Flamant G (2017) Solar pyrolysis of carbonaceous $\begin{array}{llll}\text { feedstocks: } & \text { A } & \text { 156:73-92. }\end{array}$ doi:https://doi.org/10.1016/j.solener.2017.05.033

55. Bartocci P, Tschentscher R, Stensrød RE, Barbanera M, Fantozzi F (2019) Kinetic analysis of digestate slow pyrolysis with the application of the master-plots method and independent parallel reactions scheme. Molecules 24 (9):1657. doi:https://doi.org/10.3390/molecules24091657

56. Sobek S, Werle S (2020) Kinetic modelling of waste wood devolatilization during pyrolysis based on thermogravimetric data and solar pyrolysis reactor performance. Fuel 261:116459. doi:https://doi.org/10.1016/j.fuel.2019.116459

57. Vasudev V, Ku X, Lin J (2020) Pyrolysis of algal biomass: Determination of the kinetic triplet and thermodynamic analysis. Bioresource Technology 317:124007. doi:https://doi.org/10.1016/j.biortech.2020.124007 


\section{Figures and tables}

Figure 1 - (a) Scanning electron microscopy images of H-SCB ad H-RH and (b) FT-IR spectra of $\mathrm{H}-\mathrm{SBC}$ and $\mathrm{H}-\mathrm{RH}$.

(a)
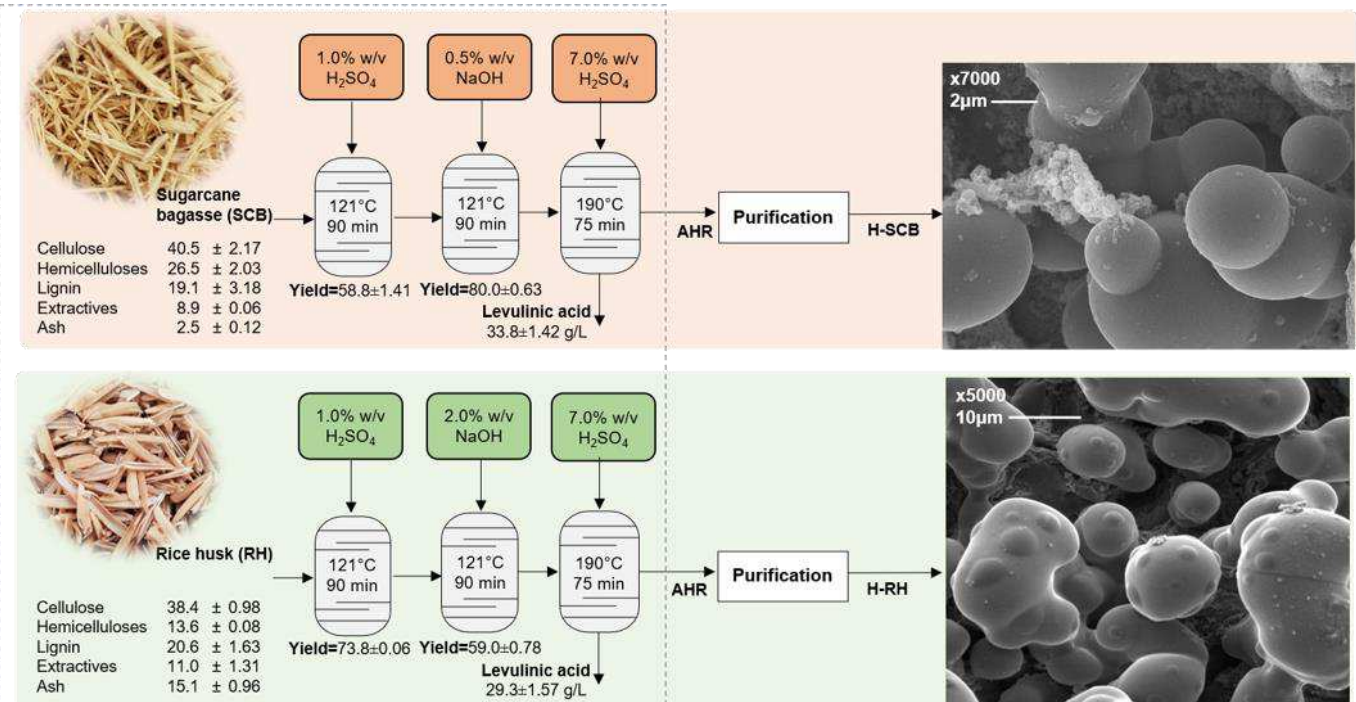

Lopes et al. [4]

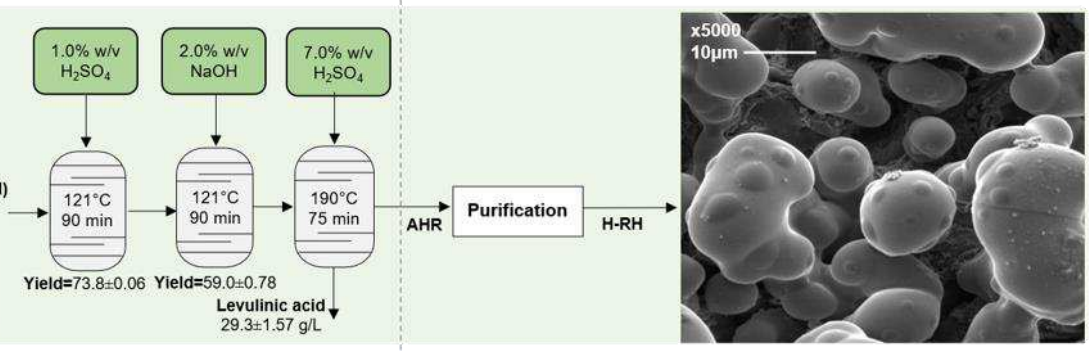

(b)

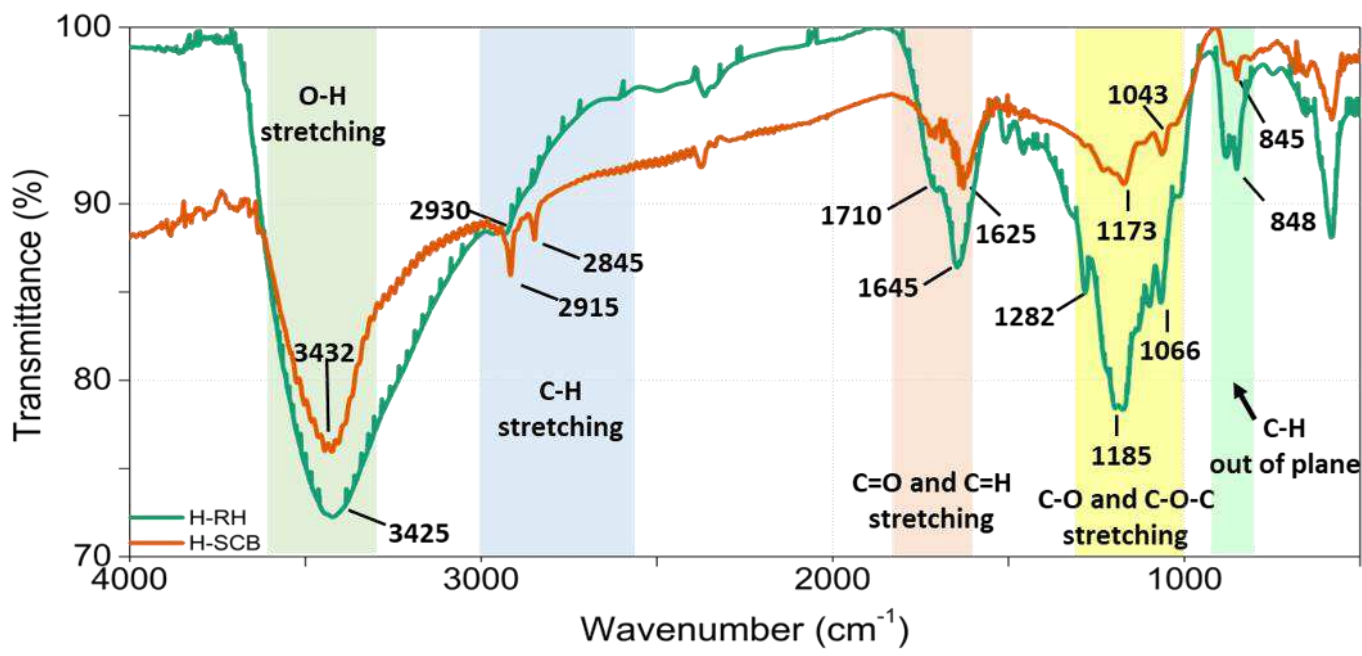


Figure 2 - Normalized mass loss and normalized DTG curves of (a) H-SCB and (b) $\mathrm{H}-\mathrm{RH}$ as a function of temperature; and QMID ion current curves for (c) $\mathrm{H}$ SCB and (d) H-RH.
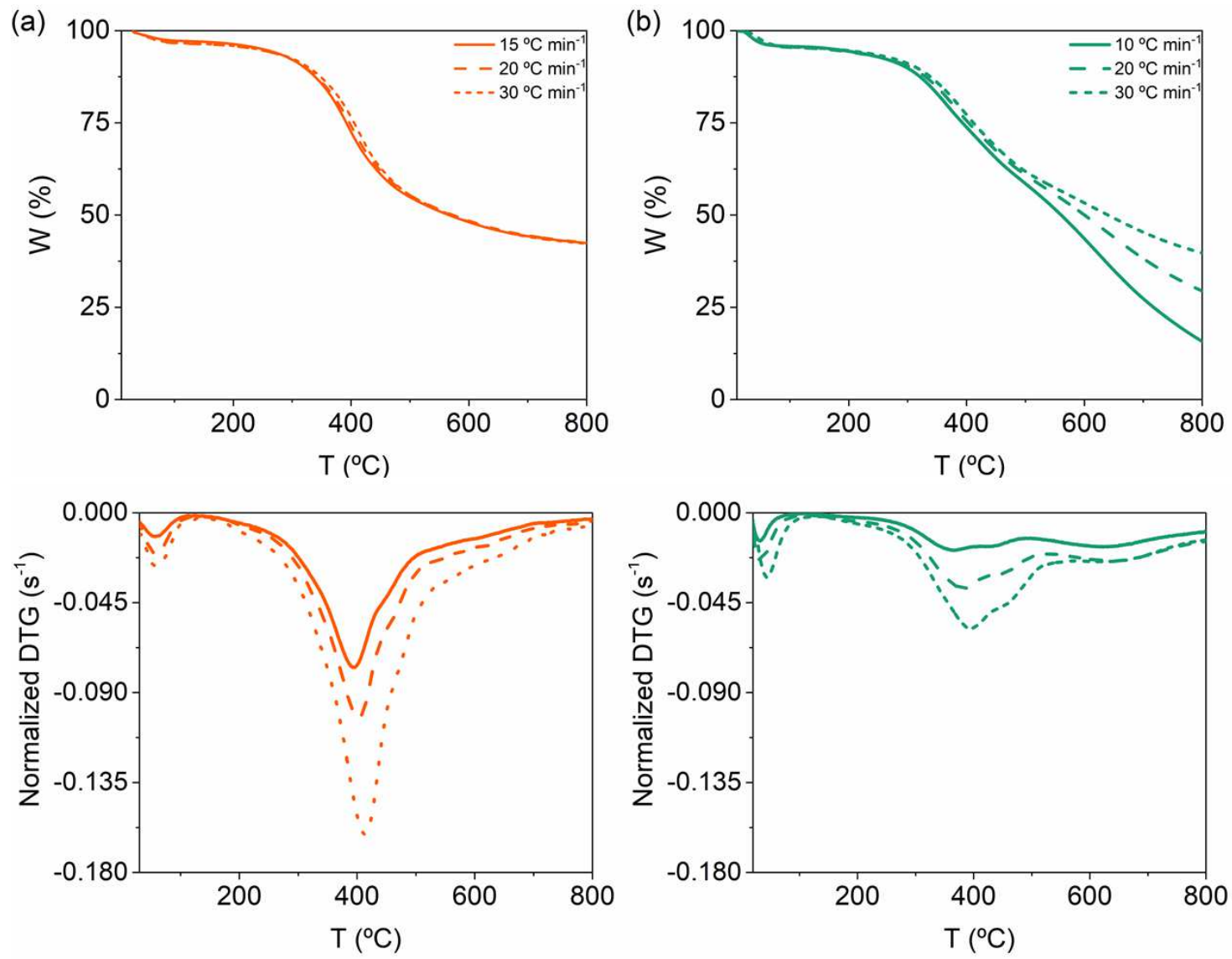

(c)

(d)
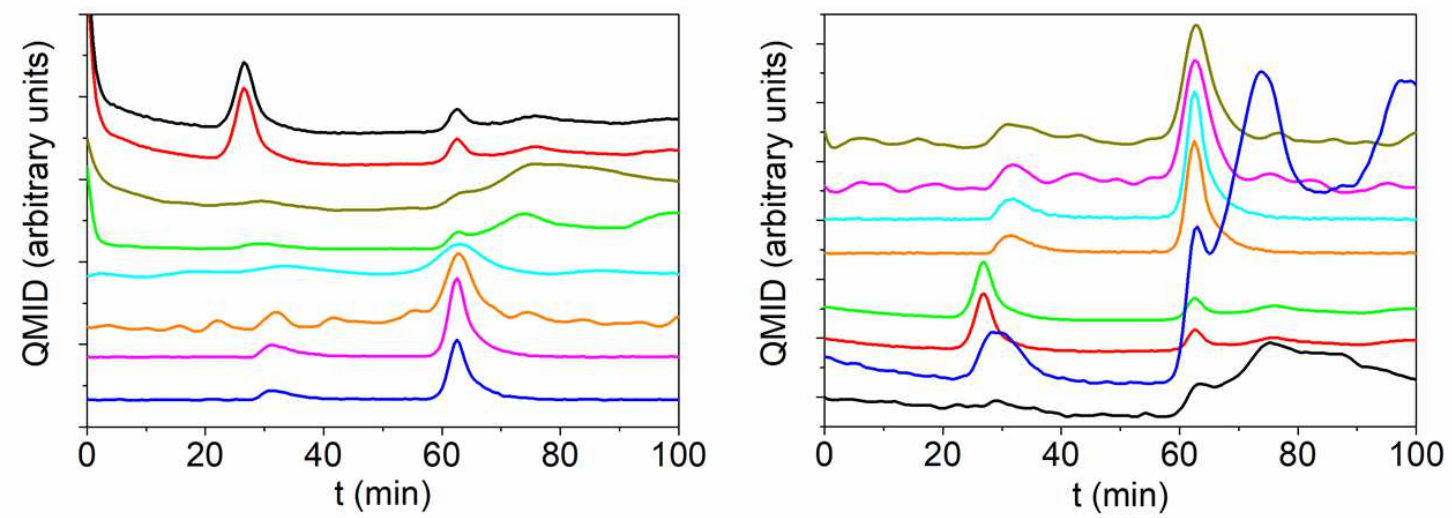

$\longrightarrow \mathrm{m} / \mathrm{z}=12 \longrightarrow \mathrm{m} / \mathrm{z}=17-\mathrm{m} / \mathrm{z}=18-\mathrm{m} / \mathrm{z}=44$ $\mathrm{m} / \mathrm{z}=48-\mathrm{m} / \mathrm{z}=50-\mathrm{m} / \mathrm{z}=64 \longrightarrow \mathrm{m} / \mathrm{z}=66$ 
Figure 3 - Linear fit of STK (left) and FWO (right) methods at different $\alpha$ values: (a) $\mathrm{H}-\mathrm{SCB}$ and (b) $\mathrm{H}-\mathrm{RH}$.
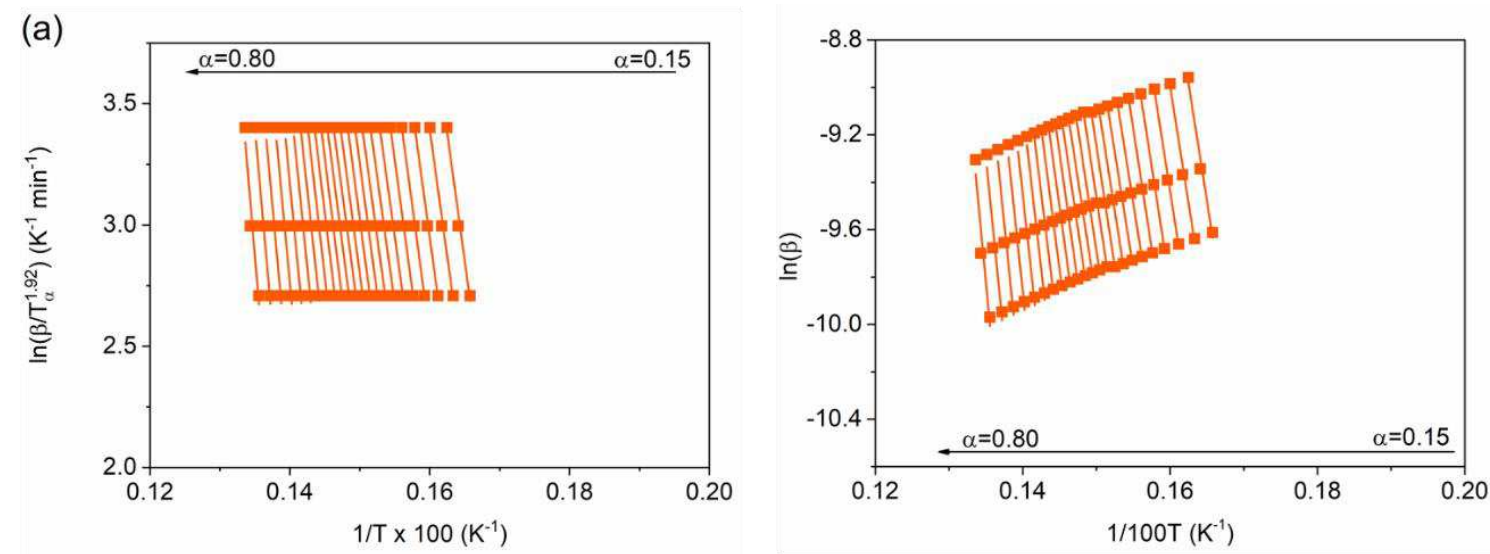

(b)
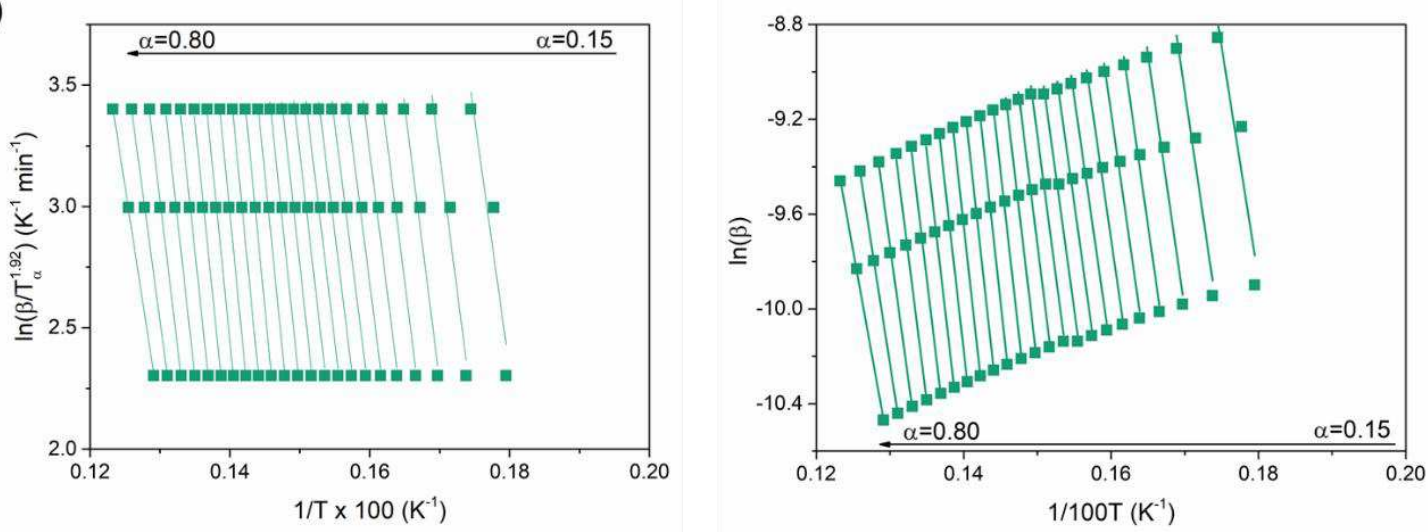
Figure 4 - Experimental and theoretical master plots (for $\beta=20^{\circ} \mathrm{C} \mathrm{min}^{-1}$ ) as a function of conversion ( $\alpha$ ) for the pyrolysis of (a) $\mathrm{H}-\mathrm{SCB}$ and (b) $\mathrm{H}-\mathrm{RH}$.
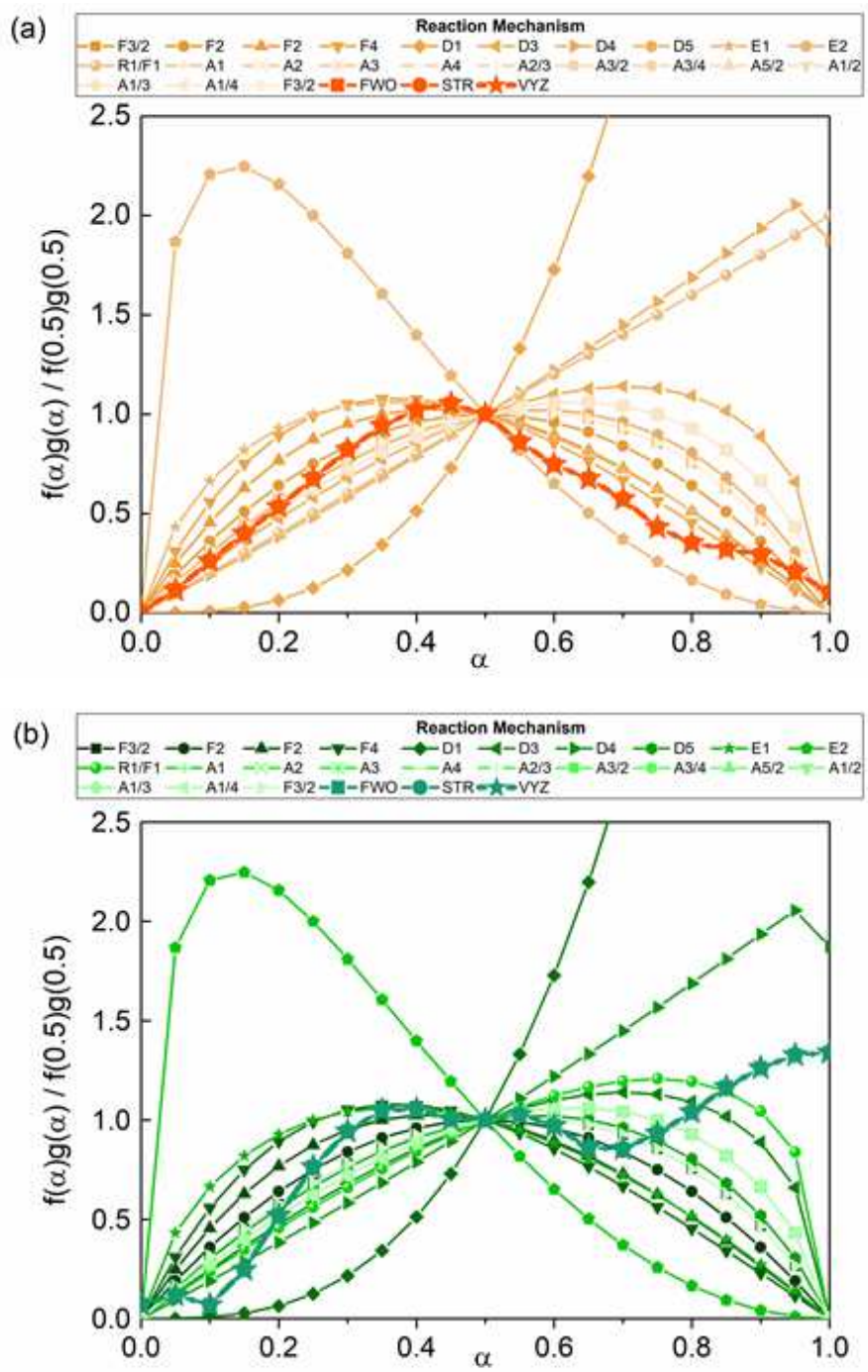
Figure $5-\Delta H_{\alpha}, \Delta G_{\alpha}$, and $\Delta S_{\alpha}$ change for $\operatorname{H-SCB}(a, b, c)$ e H-RH (d, e, f) during reaction.
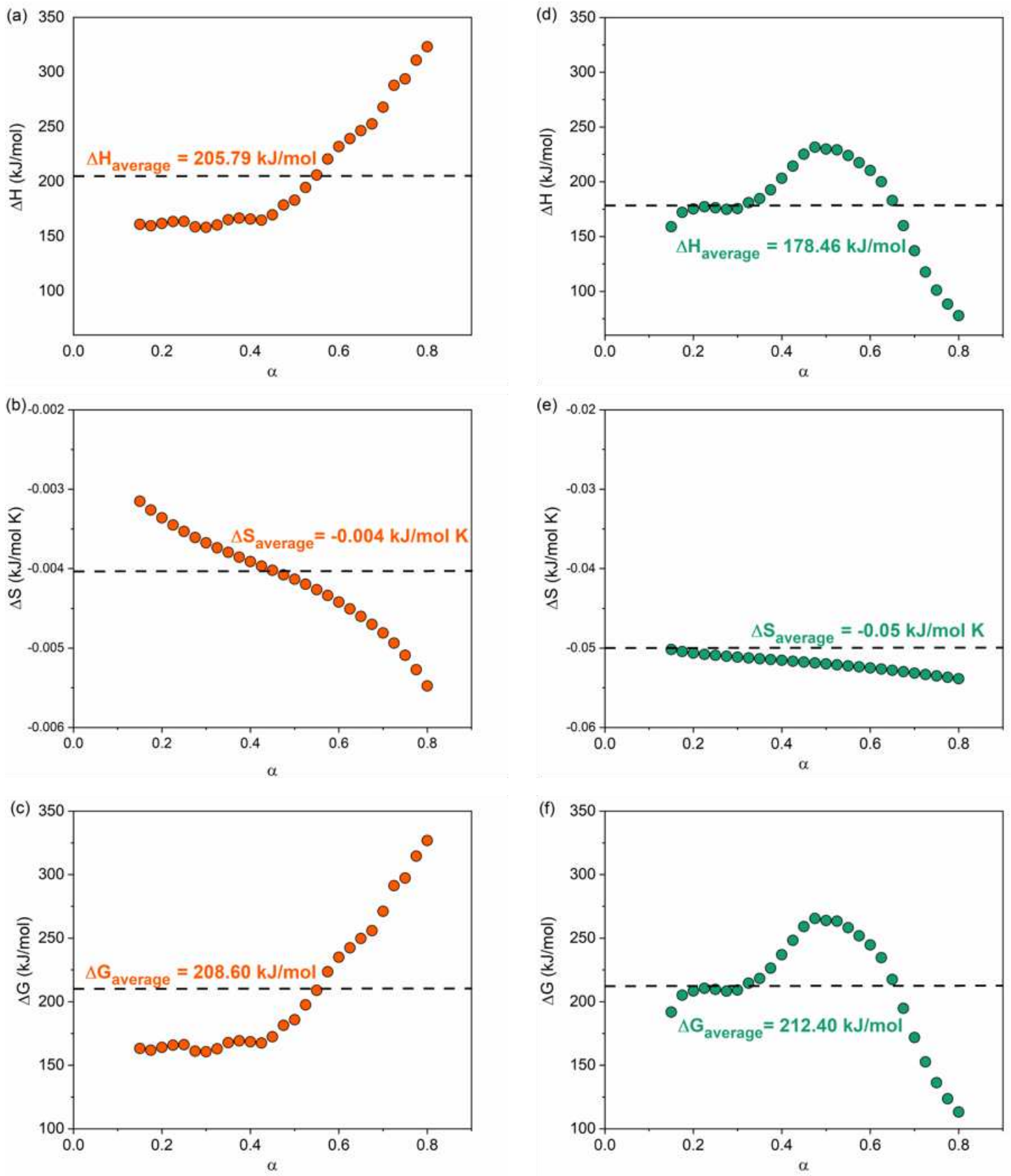
Figure 6 - Experimental (lines) and calculated (symbols) pyrolysis conversion rate curves as a function of temperature for (a) H-SCB and (b) $\mathrm{H}-\mathrm{RH}$.

(a)

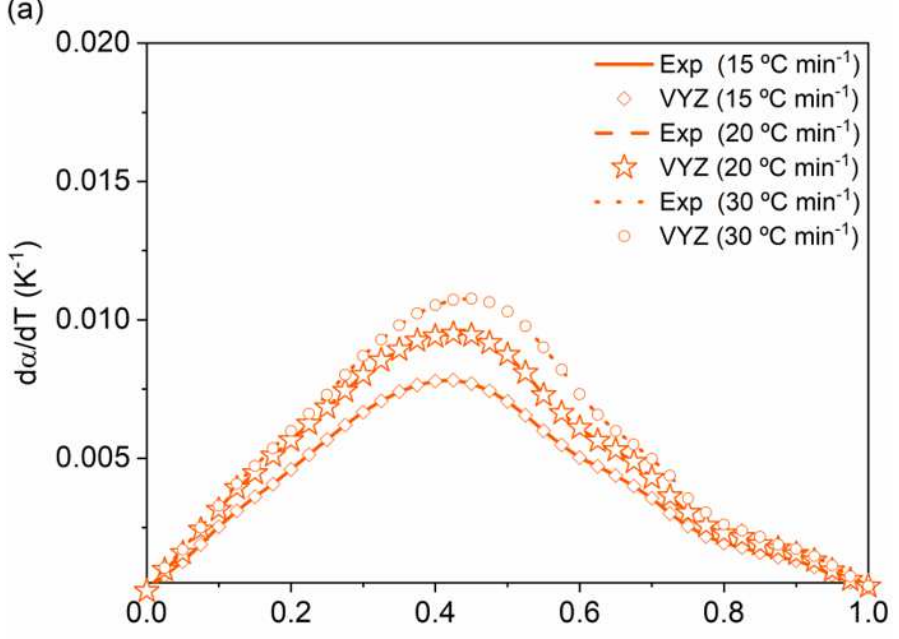

$\alpha$

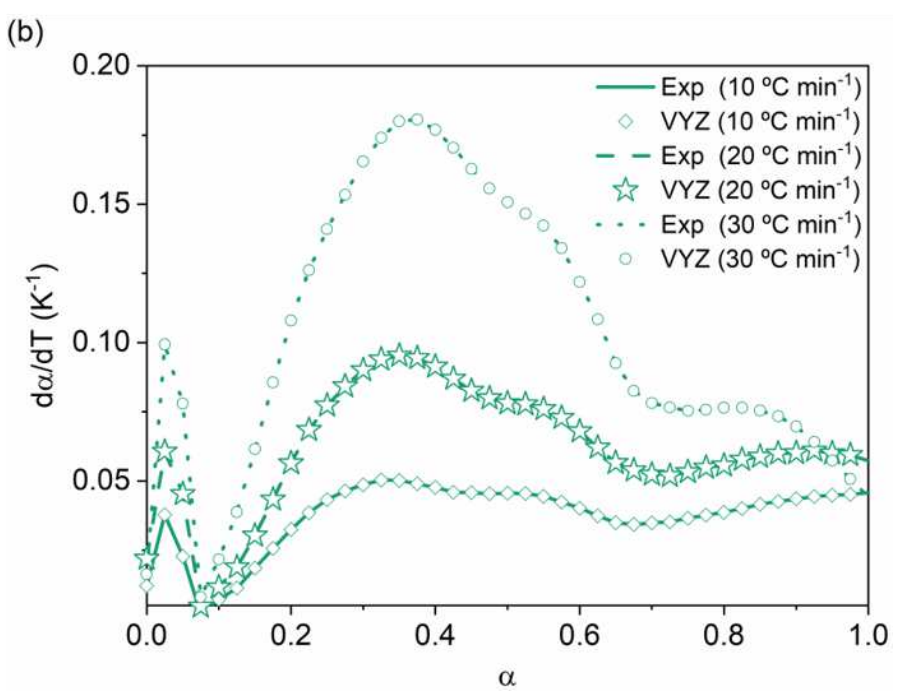


Table 1 - Kinetic mechanisms, $f(\alpha)$, and their integral forms, $g(\alpha)$, used in solidstate reactions.

\begin{tabular}{|c|c|c|c|}
\hline Model & $g(\alpha)$ & $f(\alpha)$ & Rate-determining mechanism \\
\hline 1. C & \multicolumn{3}{|c|}{ Chemical process or mechanism non-involving equations } \\
\hline $\mathrm{F}_{1 / 3}$ & $1-(1-\alpha)^{2 / 3}$ & $(3 / 2)(1-\alpha)^{1 / 3}$ & Chemical reaction \\
\hline $\mathrm{F}_{3 / 4}$ & $1-(1-\alpha)^{1 / 4}$ & $4(1-\alpha)^{3 / 4}$ & Chemical reaction \\
\hline $\mathrm{F}_{3 / 2}$ & $(1-\alpha)^{-1 / 2}-1$ & $2(1-\alpha)^{3 / 2}$ & Chemical reaction \\
\hline $\mathrm{F}_{2}$ & $(1-\alpha)^{-1}-1$ & $(1-\alpha)^{2}$ & Chemical reaction \\
\hline $\mathrm{F}_{3}$ & $(1-\alpha)^{-2}-1$ & $(1 / 2)(1-\alpha)^{3}$ & Chemical reaction \\
\hline $\mathrm{F}_{4}$ & $(1-\alpha)^{-3}-1$ & $(1 / 3)(1-\alpha)^{4}$ & Chemical reaction \\
\hline $\mathrm{G}_{1}$ & $1-(1-\alpha)^{2}$ & {$[2(1-\alpha)]^{-1}$} & Chemical reaction \\
\hline $\mathrm{G}_{2}$ & $1-(1-\alpha)^{3}$ & {$\left[3(1-\alpha)^{2}\right]^{-1}$} & Chemical reaction \\
\hline $\mathrm{G}_{3}$ & $1-(1-\alpha)^{4}$ & {$\left[4(1-\alpha)^{3}\right]^{-1}$} & Chemical reaction \\
\hline \multicolumn{4}{|c|}{ Acceleratory rate equations } \\
\hline$P_{3 / 2}$ & $\alpha^{3 / 2}$ & $(2 / 3) \alpha^{-1 / 2}$ & Nucleation (power law) \\
\hline $\mathrm{P}_{1 / 2}$ & $\alpha^{1 / 2}$ & $2 \alpha^{1 / 2}$ & Nucleation (power law) \\
\hline $\mathrm{P}_{1 / 3}$ & $\alpha^{1 / 3}$ & $3 \alpha^{2 / 3}$ & Nucleation (power law) \\
\hline $\mathrm{P}_{1 / 4}$ & $\alpha^{1 / 4}$ & $4 \alpha^{3 / 4}$ & Nucleation (power law) \\
\hline $\mathrm{P}_{2}$ & $\alpha^{2}$ & $(1 / 2) \alpha^{-1}$ & Nucleation (parabolic law) \\
\hline $\mathrm{E}_{1}$ & $\ln \alpha$ & $\alpha$ & Nucleation (exponential law) \\
\hline $\mathrm{E}_{2}$ & $\ln \alpha^{2}$ & $\alpha / 2$ & Nucleation (exponential law) \\
\hline 3. & \multicolumn{3}{|c|}{ Sigmoidal rate equations or random nucleation and subsequent growth } \\
\hline$A_{1}, F_{1}$ & $-\ln (1-\alpha)$ & $1-\alpha$ & Random nucleation/first order (Mampel) \\
\hline$A_{2 / 3}$ & {$[-\ln (1-\alpha)]^{3 / 2}$} & $(2 / 3)(1-\alpha)[-\ln (1-\alpha)]^{-1 / 2}$ & Random nucleation (Avrami-Erofeev) \\
\hline$A_{3 / 2}$ & {$[-\ln (1-\alpha)]^{2 / 3}$} & $(3 / 2)(1-\alpha)[-\ln (1-\alpha)]^{1 / 3}$ & Random nucleation (Avrami-Erofeev) \\
\hline$A_{3 / 4}$ & {$[-\ln (1-\alpha)]^{4 / 3}$} & $(3 / 4)(1-\alpha)[-\ln (1-\alpha)]^{-1 / 3}$ & Random nucleation (Avrami-Erofeev) \\
\hline$A_{5 / 2}$ & {$[-\ln (1-\alpha)]^{2 / 5}$} & $(5 / 2)(1-\alpha)[-\ln (1-\alpha)]^{3 / 5}$ & Random nucleation (Avrami-Erofeev) \\
\hline $\mathrm{A}_{2}$ & {$[-\ln (1-\alpha)]^{1 / 2}$} & $2(1-\alpha)[-\ln (1-\alpha)]^{1 / 2}$ & Random nucleation (Avrami-Erofeev) \\
\hline $\mathrm{A}_{3}$ & {$[-\ln (1-\alpha)]^{1 / 3}$} & $3(1-\alpha)[-\ln (1-\alpha)]^{2 / 3}$ & Random nucleation (Avrami-Erofeev) \\
\hline $\mathrm{A}_{4}$ & {$[-\ln (1-\alpha)]^{1 / 4}$} & $4(1-\alpha)[-\ln (1-\alpha)]^{3 / 4}$ & Random nucleation (Avrami-Erofeev) \\
\hline$A_{1 / 2}$ & {$[-\ln (1-\alpha)]^{2}$} & $(1 / 2)(1-\alpha)[-\ln (1-\alpha)]^{-1}$ & Random nucleation (Avrami-Erofeev) \\
\hline$A_{1 / 3}$ & {$[-\ln (1-\alpha)]^{3}$} & $(1 / 3)(1-\alpha)[-\ln (1-\alpha)]^{-2}$ & Random nucleation (Avrami-Erofeev) \\
\hline $\mathrm{A}_{1 / 4}$ & {$[-\ln (1-\alpha)]^{4}$} & $(1 / 4)(1-\alpha)[-\ln (1-\alpha)]^{-3}$ & Random nucleation (Avrami-Erofeev) \\
\hline $\mathrm{B}_{1}$ & $\ln [\alpha /(1-\alpha)]$ & $\alpha /(1-\alpha)$ & Branching nuclei (Prout-Tompkins) \\
\hline \multicolumn{4}{|c|}{ 4. Deceleratory rate equations (phase boundary reaction) } \\
\hline $\mathrm{R}_{1}, \mathrm{~F}_{0}, \mathrm{P}_{1}$ & $\alpha \quad \alpha$ & 1 & Contracting disk \\
\hline $\mathrm{R}_{2}, \mathrm{~F}_{1 / 2}$ & $1-(1-\alpha)^{1 / 2}$ & $\left.2(1-\alpha)^{1 / 2}\right]$ & Contracting cylinder \\
\hline$R_{3}, F_{2 / 3}$ & $1-(1-\alpha)^{1 / 3}$ & $3(1-\alpha)^{2 / 3}$ & Contracting sphere \\
\hline \multicolumn{4}{|c|}{ Deceleratory rate equations (equations based on the diffusion mechanism) } \\
\hline $\mathrm{D}_{1}$ & $\alpha^{2}$ & $1 /(2 \alpha)$ & One-dimensional diffusion \\
\hline $\mathrm{D}_{2}$ & $\alpha+(1-\alpha) \ln (1-\alpha)$ & {$[-\ln (1-\alpha)]^{-1}$} & Three-dimensional diffusion \\
\hline$D_{3}$ & {$\left[1-(1-\alpha)^{1 / 3}\right]^{2}$} & $(3 / 2)(1-\alpha)^{2 / 3}\left[1-(1-\alpha)^{1 / 3}\right]^{-1}$ & Three-dimensional diffusion (Jander) \\
\hline $\mathrm{D}_{4}$ & $1-(2 / 3) \alpha-(1-\alpha)^{2 / 3}$ & $\quad(3 / 2)\left[(1-\alpha)^{1 / 3}-1\right]^{-1}$ & $\begin{array}{c}\text { Three-dimensional diffusion } \\
\text { (Ginstling-Brounshtein) }\end{array}$ \\
\hline$D_{5}$ & {$\left[(1-\alpha)^{-1 / 3}-1\right]^{2}$} & $(3 / 2)(1-\alpha)^{4 / 3}\left[(1-\alpha)^{1 / 3}-1\right]^{-1}$ & Three-dimensional diffusion (Crank) \\
\hline$D_{6}$ & {$\left[(1+\alpha)^{1 / 3}-1\right]^{2}$} & $(3 / 2)(1+\alpha)^{1 / 3}\left[(1+\alpha)^{1 / 3}-1\right]^{-1}$ & Three-dimensional diffusion \\
\hline $\mathrm{D}_{7}$ & $1-(2 / 3) \alpha-(1+\alpha)^{2 / 3}$ & $(3 / 2)\left[(1+\alpha)^{-1 / 3}-1\right]^{-1}$ & Three-dimensional diffusion \\
\hline$D_{8}$ & {$\left[(1+\alpha)^{-1 / 3}-1\right]^{2}$} & $(3 / 2)(1+\alpha)^{4 / 3}\left[(1+\alpha)^{1 / 3}-1\right]^{-1}$ & Three-dimensional diffusion \\
\hline
\end{tabular}

Fonte: Adapted from Trache et al. [32] 
Table 2 - Proximate and ultimate analysis and higher heating value of $\mathrm{H}-\mathrm{SCB}$ and $\mathrm{H}-\mathrm{RH}$.

\begin{tabular}{|c|c|c|}
\hline Parameters & H-SCB & H-RH \\
\hline \multicolumn{3}{|c|}{ Proximate Analysis (\%, dry basis*) } \\
\hline Moisture & $4.78 \pm 0.40^{a}$ & $4.32 \pm 0.60^{a}$ \\
\hline Volatile Matter * & $57.00 \pm 1.06^{a}$ & $54.19 \pm 0.97^{b}$ \\
\hline Fixed Carbon * & $38.68 \pm 1.37^{a}$ & $40.15 \pm 0.68^{a}$ \\
\hline Ash * & $4.32 \pm 0.31^{a}$ & $5.65 \pm 0.30^{b}$ \\
\hline \multicolumn{3}{|c|}{ Ultimate analysis (\%, dry basis) } \\
\hline C & $60.61 \pm 0.90^{a}$ & $60.84 \pm 0.25^{a}$ \\
\hline $\mathrm{H}$ & $4.84 \pm 0.04^{a}$ & $4.67 \pm 0.06^{b}$ \\
\hline $\mathrm{O}$ & $29.55 \pm 0.53^{a}$ & $28.10 \pm 0.50^{b}$ \\
\hline $\mathrm{H} / \mathrm{C}$ & $0.94 \pm 0.02$ & $0.91 \pm 0.01^{\mathrm{a}}$ \\
\hline $\mathrm{O} / \mathrm{C}$ & $0.37 \pm 0.01$ & $0.35 \pm 0.01^{\mathrm{a}}$ \\
\hline $\mathrm{HHV}\left(\mathrm{MJ} \mathrm{kg}^{-1}\right)$ & 22.45 & 24.70 \\
\hline
\end{tabular}

Groups followed by the same letter (overwritten) are not significantly different at $p<0.05$ by ANOVA and complemented by Tukey's test. The deviation in HHV was less than $1 \%$.

*Data expressed on a dry basis. 
Table 3 - Activation energies $\left(E_{a \alpha}, \mathrm{kJ} \mathrm{mol}^{-1}\right)$ obtained for the thermal/pyrolyis degradation of humins.

\begin{tabular}{|c|c|c|c|c|c|c|c|c|c|c|c|c|}
\hline \multirow{3}{*}{$\begin{array}{c}\text { Method } \\
\alpha \\
\end{array}$} & \multicolumn{4}{|c|}{ STK } & \multicolumn{4}{|c|}{ FWO } & \multicolumn{4}{|c|}{ VYZ } \\
\hline & \multicolumn{2}{|c|}{ H-SCB } & \multicolumn{2}{|c|}{ H-RH } & \multicolumn{2}{|c|}{ H-SCB } & \multicolumn{2}{|c|}{ H-RH } & \multicolumn{2}{|c|}{ H-SCB } & \multicolumn{2}{|c|}{ H-RH } \\
\hline & $\mathbf{E}_{\mathbf{a} \alpha}$ & $\mathbf{R}^{2}$ & $\mathbf{E}_{\mathrm{a} \alpha}$ & $\mathbf{R}^{2}$ & $\mathbf{E}_{\mathrm{a} \alpha}$ & $\mathbf{R}^{2}$ & $\mathbf{E}_{\mathbf{a} \alpha}$ & $\mathbf{R}^{2}$ & $\mathbf{E}_{\mathbf{a} \alpha}$ & $\mathbf{R}^{2}$ & $E_{a \alpha}$ & $\mathbf{R}^{2}$ \\
\hline 0.150 & 166.12 & 0.99 & 163.11 & 0.90 & 164.63 & 0.99 & 162.44 & 0.89 & 166.09 & 0.99 & 163.61 & 0.99 \\
\hline 0.175 & 165.00 & 0.99 & 175.99 & 0.96 & 163.30 & 0.99 & 175.68 & 0.96 & 164.76 & 0.99 & 176.93 & 0.98 \\
\hline 0.200 & 167.25 & 1.00 & 179.25 & 0.98 & 165.53 & 1.00 & 178.89 & 0.98 & 167.01 & 0.99 & 180.16 & 0.98 \\
\hline 0.225 & 169.04 & 1.00 & 181.46 & 0.99 & 167.28 & 1.00 & 181.03 & 0.99 & 168.77 & 0.99 & 182.32 & 0.98 \\
\hline 0.250 & 169.39 & 1.00 & 180.79 & 0.99 & 167.54 & 1.00 & 180.16 & 0.99 & 169.04 & 0.99 & 181.45 & 0.98 \\
\hline 0.275 & 164.82 & 1.00 & 179.63 & 0.99 & 162.63 & 1.00 & 178.80 & 0.99 & 164.09 & 0.99 & 180.09 & 0.98 \\
\hline 0.300 & 164.45 & 1.00 & 180.49 & 0.99 & 162.15 & 1.00 & 179.57 & 0.99 & 163.60 & 0.99 & 180.87 & 0.98 \\
\hline 0.325 & 166.65 & 1.00 & 185.78 & 0.99 & 164.38 & 1.00 & 185.00 & 0.99 & 165.85 & 0.99 & 186.33 & 0.98 \\
\hline 0.350 & 171.27 & 1.00 & 189.42 & 0.99 & 169.16 & 1.00 & 188.70 & 0.99 & 170.67 & 0.99 & 190.05 & 0.98 \\
\hline 0.375 & 172.73 & 1.00 & 197.24 & 0.99 & 170.61 & 1.00 & 196.79 & 0.99 & 172.14 & 0.99 & 198.19 & 0.98 \\
\hline 0.400 & 172.16 & 1.00 & 207.32 & 0.99 & 169.94 & 1.00 & 207.26 & 0.99 & 171.46 & 0.99 & 208.71 & 0.98 \\
\hline 0.425 & 171.30 & 1.00 & 218.13 & 0.99 & 168.96 & 0.99 & 218.49 & 0.99 & 170.47 & 0.99 & 219.98 & 0.98 \\
\hline 0.450 & 175.91 & 1.00 & 228.57 & 1.00 & 173.75 & 1.00 & 229.34 & 1.00 & 175.30 & 0.99 & 230.86 & 0.98 \\
\hline 0.475 & 184.51 & 0.99 & 234.79 & 1.00 & 182.72 & 0.99 & 235.74 & 1.00 & 184.34 & 0.99 & 237.28 & 0.98 \\
\hline 0.500 & 188.74 & 1.00 & 233.40 & 1.00 & 187.08 & 0.99 & 234.13 & 1.00 & 188.74 & 0.99 & 235.68 & 0.98 \\
\hline 0.525 & 199.82 & 0.99 & 232.96 & 1.00 & 198.66 & 0.99 & 233.53 & 1.00 & 200.39 & 0.99 & 235.09 & 0.98 \\
\hline 0.550 & 210.70 & 0.99 & 228.24 & 1.00 & 210.02 & 0.99 & 228.42 & 1.00 & 211.81 & 0.99 & 229.99 & 0.98 \\
\hline 0.575 & 224.70 & 0.98 & 222.26 & 1.00 & 224.66 & 0.97 & 221.99 & 1.00 & 226.49 & 0.99 & 223.55 & 0.98 \\
\hline 0.600 & 235.69 & 0.96 & 215.70 & 1.00 & 236.12 & 0.96 & 214.93 & 1.00 & 237.97 & 0.99 & 216.46 & 0.98 \\
\hline 0.625 & 242.75 & 0.95 & 206.28 & 1.00 & 243.43 & 0.95 & 204.84 & 1.00 & 245.31 & 0.99 & 206.32 & 0.98 \\
\hline 0.650 & 249.85 & 0.96 & 190.42 & 1.00 & 250.77 & 0.95 & 187.97 & 1.00 & 252.66 & 0.99 & 189.28 & 0.98 \\
\hline 0.675 & 255.77 & 0.95 & 169.31 & 1.00 & 256.87 & 0.95 & 165.57 & 1.00 & 258.78 & 0.99 & 166.52 & 0.98 \\
\hline 0.700 & 270.46 & 0.94 & 148.27 & 1.00 & 272.18 & 0.94 & 143.22 & 1.00 & 274.11 & 0.99 & 143.61 & 0.98 \\
\hline 0.725 & 289.75 & 0.89 & 130.79 & 1.00 & 292.31 & 0.89 & 124.62 & 1.00 & 294.24 & 0.99 & 124.37 & 0.98 \\
\hline 0.750 & 295.57 & 0.87 & 116.01 & 1.00 & 298.23 & 0.86 & 108.85 & 0.99 & 300.19 & 1.00 & 107.98 & 0.98 \\
\hline 0.775 & 312.12 & 0.77 & 104.71 & 0.99 & 315.40 & 0.75 & 96.74 & 0.99 & 317.38 & 1.00 & 95.44 & 0.98 \\
\hline 0.800 & 324.12 & 0.73 & 95.259 & 0.99 & 327.75 & 0.72 & 86.58 & 0.99 & 329.76 & 1.00 & 84.99 & 0.98 \\
\hline Average & \multicolumn{2}{|c|}{$210.39 \pm 51.78$} & \multicolumn{2}{|c|}{$185.02 \pm 39.19$} & \multicolumn{2}{|c|}{$210.14 \pm 53.68$} & \multicolumn{2}{|c|}{$183.31 \pm 41.76$} & \multicolumn{2}{|c|}{$211.53 \pm 53.89$} & \multicolumn{2}{|c|}{$184.30 \pm 42.59$} \\
\hline
\end{tabular}


Table 4 - Root mean squared error (RMSE) between theorical and experimental master-plots calculated by VYZ method. Models marked with an " " were plotted in Figure 4.

\begin{tabular}{|c|c|c|c|c|c|c|c|c|}
\hline $\begin{array}{l}\text { Mechanis } \\
\text { m }\end{array}$ & H-SCB & H-RH & $\begin{array}{l}\text { Mechanis } \\
\text { m }\end{array}$ & H-SCB & H-RH & $\begin{array}{l}\text { Mechanis } \\
\text { m }\end{array}$ & H-SCB & H-RH \\
\hline$F_{1 / 3}$ & 0.446 & 0.244 & $D_{2}$ & 0.457 & 0.252 & E2 & 0.825 & 0.893 \\
\hline$F_{3 / 4}$ * & 0.343 & 0.167 & $D_{3}$ * & 0.362 & 0.179 & $A_{1}$ & 0.295 & 0.142 \\
\hline$F_{3 / 2}$ * & 0.220 & 0.131 & $\mathrm{D}_{4}$ * & 0.588 & 0.369 & $A_{2}$ & 0.295 & 0.142 \\
\hline $\mathbf{F}_{2} *$ & 0.172 & 0.151 & $D_{5}$ * & 0.242 & 0.129 & $A_{3}$ & 0.295 & 0.142 \\
\hline $\mathbf{F}_{3}$ * & 0.149 & 0.211 & $\mathbf{D}_{6}$ & 0.591 & 0.373 & $\mathbf{A}_{4}$ & 0.295 & 0.142 \\
\hline$F_{4}$ * & 0.187 & 0.268 & $D_{7}$ & 0.578 & 0.361 & $A_{2 / 3}$ & 0.295 & 0.142 \\
\hline $\mathbf{G}_{1}$ & 1.088 & 0.849 & $D_{8}$ & 0.635 & 0.416 & $A_{3 / 2}$ & 0.295 & 0.142 \\
\hline $\mathbf{G}_{2}$ & 2.278 & 2.033 & $\mathbf{P}_{2 / 3}$ & 0.553 & 0.336 & $A_{3 / 4}$ & 0.295 & 0.142 \\
\hline $\mathbf{G}_{3}$ & 5.058 & 4.816 & $\mathbf{P}_{1 / 2}$ & 0.553 & 0.336 & $A_{5 / 2}$ & 0.295 & 0.142 \\
\hline $\mathbf{R}_{\mathbf{1}} / \mathbf{F}_{\mathbf{0}}$ & 0.553 & 0.336 & $\mathbf{P}_{1 / 3}$ & 0.553 & 0.336 & $A_{1 / 2}$ & 0.295 & 0.142 \\
\hline $\mathbf{R}_{2} / \mathbf{F}_{1 / 2}$ & 0.402 & 0.208 & $\mathbf{P}_{1 / 4}$ & 0.553 & 0.336 & $A_{1 / 3}$ & 0.295 & 0.142 \\
\hline $\mathbf{R}_{3} / \mathbf{F}_{2 / 3}$ & 0.362 & 0.179 & $\mathbf{P}_{2}$ & 0.553 & 0.336 & $A_{1 / 4}$ & 0.295 & 0.142 \\
\hline$D_{1}$ & 1.527 & 1.292 & $E_{1}$ * & 0.213 & 0.263 & $\mathbf{B}_{1}$ & - & - \\
\hline
\end{tabular}




\section{Supplementary Files}

This is a list of supplementary files associated with this preprint. Click to download.

- SupplementaryMaterial.docx 